\title{
Influence of Zno nanoparticle addition and Spark Peak Current on EDM Process of AISI 1045, AISI 4140, and AISI D3: MRR, Surface Roughness, and Surface Texture
}

\author{
Masoud Pour ( $\nabla$ m.pour@qiet.ac.ir) \\ Quchan University of Technology \\ S. Mohammad Javadi \\ Ehsan Layegh K.
}

\section{Research Article}

Keywords: EDM process, ZnO nanoparticle, MRR, Surface roughness

Posted Date: May 6th, 2021

DOl: https://doi.org/10.21203/rs.3.rs-469641/v1

License: (c) (i) This work is licensed under a Creative Commons Attribution 4.0 International License.

Read Full License 


\section{Abstract}

In the recent studies, the effects of different metal oxide nanoparticles addition in different dielectrics of EDM process has been thoroughly investigated, showing that adding the nanoparticles improves the material removal rate and surface roughness. The results illustrate that the parameters such as density, particle size, particle concentration, and electrical and thermal conductivity of the nanoparticles can affect the process performance. Compared to the other metal oxides, $\mathrm{ZnO}$ has lower thermal and higher electrical resistance which makes it distinct from other nanoparticles used in EDM process in terms of physical properties. In this paper, the effects of the variation of peak current,and $\mathrm{ZnO}$ particle mass on MRR, surface roughness, and thermal conductivity of AISI1045区 AISI4140, and AISID3 in EDM process are investigated. The results illustrate that 4 grams of the $\mathrm{ZnO}$ nanoparticle mass increase the MRR up to $10.71 \%, 50 \%$, and $45.55 \%$, for rough machining of AISI 1045, AISI4140, and AISID3, respectively. In finish machining, they show that the surface roughness can be improved $16.66 \%, 29.41 \%$, and $56.25 \%$, respectively. It is observed that the amount of deposited particles on AISID3 is maximum followed by AISI 1045 and AISI4140. Therefore, in AISID3 both significant improvement of surface roughness and ZnO deposition can be achieved.

\section{Introduction}

Nowadays, the application of high-hardness materials with high mechanical and thermal resistances for improving the performance of components in various industries, such as the biomedical, the aerospace, and the oil and gas sectors, is extensively increased. Some of those materials can be mentioned as: composites, tool steels, carbides, and ceramics. The electrical discharge machining (EDM) process has been widely used in the manufacturing process of the mentioned materials thus its improvement through modern approaches has been considered by many researchers. In this manufacturing technique, a strong electric field is generated between the electrode and the workpiece to have the dielectric molecules polarized and oriented, so that the electrons flow in the form of a plasma discharge channel upon discharging the peak current.

The generated heat and pressure during this process leads to material removal due to the release of the kinetic energy from the existing electrons and ions [1,2]. This extraordinary amount of heat tends to melt, vaporize, and eventually wear the tool as well as the workpiece [3]. Although the EDM process has many advantages, it has some disadvantages that have limited its widespread application. The most important drawbacks are low material removal rate (MRR), surface instability due to thermal stresses and thermal cracking, and failure to establish desirable workpiece surface quality [4]. As an approach to address some of the mentioned disadvantages, the use of powdered mixtures of conductor and nonconductor materials [5] in different liquids such as kerosene and deionized water [6] has been proposed since three decades ago.

These approaches are focused on reducing the electrical resistance and increasing the thermal conductivity of the dielectric liquid. Therefore, the presence of the nanoparticles cause to enhances the 
discharge frequency [7], accelerates the spark ignition and increases the overall MRR [8]. An important remark is that different powders generate different effects on the EDM performance [9]. These effects include improving on the surface quality and material removal rate, inhibiting or significantly reducing the formation of micro-sized cracks on the surface and reducing tool wear rate (TWR). The size, density, material, electrical conductivity, and thermal conductivity of the powder are the main parameters affecting the mentioned improvements of the nano powder-mixed electrical discharge machining (NPMEDM) process.

Although the effects of the particle size are yet to be adequately evaluated, some of the investigations reveal that the MRR decreases with increasing the nanoparticle size [10]. Moreover, adding nano powder to the dielectrics of EDM process improves the surface quality of the manufactured workpiece [11]. The effects of the added nanoparticle mass on the optimization of the machining performance in terms of the MRR, the surface roughness, and the formation of microcracks and micro holes, under various operating conditions (e.g., currency and pulse-on time) have been explored in the literature [12-14].

The effects of the various material powders such as aluminum oxide, titanium carbide, copper, carbon, germanium, silicon, silicon carbide, chromium, and tungsten have been investigated considering the kerosene, as the dielectric [15-22]. Although some of the above-mentioned materials have superior performance, the cost of using them is a significant restriction. Therefore, it is necessary to seek workarounds to make them cost-effective. To address this problem, some nanoparticles such as SWCNT, MWCNT and $\mathrm{Al}_{2} \mathrm{O}_{3}$ have been suggested and some studies about them have been summarized below.

The so-called single-walled and multi-walled carbon nanotubes (SWCNTs and MWCNTs) are among the most discussed nanoparticles for machining AISI D2 [23], INCONEL 825 [24, 25], AISI H13 [26], and NAK80 [27] steel alloys due to the development of uniform and excellent surface conditions at high thermal and electrical conductivities. It is showed that the addition of the SWCNT at $4 \mathrm{~g} / \mathrm{L}$ can improve the MRR and the surface roughness of the AISI D2 by $80 \%$ and $67 \%$, respectively [28]. The MWCNT particles are used for machining the AISI H13, leading to lower tool wear along with better workpiece surface morphology and MRR [26]. The effects of adding MWCNT are investigated in the machining of NAK 80 steel alloy, where the focus is on the surface quality and MRR [27]. The results indicated that adding $70 \%$ and $66 \%$ MWCNT improves surface quality and MRR, simultaneously.

Although all the previous mentioned research works have referred to the nanoparticles with high electrical and thermal conductivity to improving the machining performance, studies on the low-conductive nanopowders have also led to promising results. Among the nanoparticles with low thermal conductivity, only a few research-works have considered the aluminum oxide $\left(\mathrm{Al}_{2} \mathrm{O}_{3}\right)$ nanopowder particularly for the EDM process [15, 29-31]. It has been shown that this nanoparticle can improve the machining performance of the INCONEL 825 alloy in terms of MRR and surface roughness by $57 \%$ and $63 \%$, respectively [29]. The corresponding improvements for AISI D2, is reported as $43.5 \%$ and $33.7 \%$ better MRR and surface roughness, respectively [24]. 
A comparison between the results reported in literature implies that the MRR and surface roughness are more favourable with the SWCNTs rather than the aluminium oxide by almost $50 \%[11,32]$. However, the advantages of the deposited aluminium oxide on the surface of the steel alloy workpieces have not been investigated yet. The advantage is improving the wear resistance of the machined surface which makes it suitable for heavy duty application.

The researchers conducted several experiments to compare the effects of different nanoparticles, including the titanium oxide, the zinc oxide, and the aluminium oxide, in the machining of AISI H13 [33]. It is shown that the zinc oxide improves tool wear and MRR compared to the other mentioned materials.

The present research investigates the effects of thermal conductivity, workpiece material, steel density, nanoparticle mass, and peak current of spark on the performance of EDM process on three steel alloys, namely AISI 1045, AISI 4140, and AISI D2. For this purpose, firstly, the zinc oxide nanoparticles are synthesized. After that, their formation and particle size through XRD and DLS analyses are verified. In each stage, the effects of changes in the dispersed nanoparticle mass (in kerosene as the dielectric), peak current, and workpiece material on the developed surface roughness, MRR, and texture quality are evaluated.

The operators usually compromise between MRR and surface roughness when they select machining conditions. This paper aims to determine the optimum addition of $\mathrm{ZnO}$ mass to the dielectric so that both the higher MRR and improved surface quality (in finishing operation) of the manufactured workpiece can be achieved. Although these two parameters are dependent on many machining parameters, in this paper these two parameters are discussed based on the thermal conductivity and density of the workpieces, thermal stresses and surface cracks created on the workpiece surface.

\section{Materials And Methods}

This research work is focused on the $\mathrm{ZnO}$ nanoparticle due to its tendency to be deposited on the surface of steel leading to reducing the friction coefficient and hence increase the service life of the parts [34]. Another reason to select the $\mathrm{ZnO}$ nanoparticle is the significant difference between the thermal conductivity and electrical resistance of this metal oxide compared to other nanoparticles (e.g., $\mathrm{TiO}_{2}$ and

$\mathrm{Al}_{2} \mathrm{O}_{3}$ ) used in NPMEDM [30]. To better understand the differences between this nanoparticle and some of the other nanoparticles reviewed in the literature, electrical resistance, and thermal conductivity properties are tabulated in Table 1.

Table 1. The electrical resistance and thermal conductivity of some of the nanoparticles [35-37] 


\begin{tabular}{|lll|}
\hline $\begin{array}{l}\text { Thermal conductivity } \\
()\end{array}$ & $\begin{array}{l}\text { Electrical resistance } \\
()\end{array}$ & Nano particle \\
\hline 25.1 & 103 & $\mathrm{Al}_{2} \mathrm{O}_{3}$ \\
\hline 401 & 1.71 & $\mathrm{Cu}$ \\
\hline 4000 & 50 & CNTs \\
\hline 2 & 270 & ZnO \\
\hline
\end{tabular}

In this research work, the benefits of deposited $\mathrm{ZnO}$ nanoparticles on the steel surface of the workpiece due to the generated heat during the sparking process have been investigated. The advantages of using $\mathrm{ZnO}$ nanoparticle in roughing and finishing EDM operations have been investigated under different peak currents. The Zno nanoparticles have been prepared by chemical precipitation method which is suggested in the literature [38]. This empirical method is fairly common in the industry for the synthesis of the $\mathrm{ZnO}$ nanoparticles due to being economical and efficient. After the synthesis stage, XRD analysis is performed to verify the produced nanomaterial. The results of XRD experiment are compared with the similar works in the literature to confirm the formation of the nanoparticles (see Figure 1) [39]. In the next step, DLS experiments are performed to measure the particle size distribution. Based on the results (Figure 2), the average particle size is found to be about $400 \mathrm{~nm}$.

Subsequently, in order to suspend the $\mathrm{ZnO}$ nanoparticles in the kerosene, ultrasonic excitation is applied at $200 \mathrm{~Hz}$ for a total duration of 75 minutes. For this purpose, excitation time (On time) and resting times (Off time) are set to be 7 and 3 seconds, respectively. The samples are placed in a beaker and a coldwater bath to keep the kerosene temperature under control and hence prevent any fire. Figure 3 demonstrates the ultrasonic instrument during the excitation phase.

The machining conditions and parameters such as peak current, the $\mathrm{ZnO}$ nanoparticle mass, and workpieces material are provided in Table 2. All the experiments are conducted with copper electrodes at an operating voltage of $80 \mathrm{~V}$ for 3 minutes. In all the experiments the electrode are set as anode. Because based on the results presented in the literature, a higher surface roughness quality can be created when the electrode acts as an anode [39].

Table 2. Machining parameters and conditions 


\begin{tabular}{|lllllll|}
\hline $\begin{array}{l}\text { Electrode } \\
\text { dimensions }(\mathrm{mm})\end{array}$ & Voltage(V) & $\begin{array}{l}\text { On time } \\
(\mathrm{Sec})\end{array}$ & $\begin{array}{l}\text { Off time } \\
(\mathrm{Sec})\end{array}$ & $\begin{array}{l}\text { Peak } \\
\text { current } \\
(\mathrm{A})\end{array}$ & $\begin{array}{l}\text { Nanoparticle } \\
\text { mass }(\mathrm{g})\end{array}$ & Material \\
\hline $10 \times 10$ & 80 & 3 & 7 & 6,12, & $1,2,3,4$ & AISI \\
& & & & 18,24 & & $\begin{array}{c}\text { AISI } \\
\end{array}$ \\
& & & & & 4140 \\
& & & & & AISI D3 \\
\hline
\end{tabular}

In order to control the test conditions, each dielectric is utilized for only one set of experiments including five replicates. To ensure the uniformity of the test conditions, the tools are prepared by grinding and turning processes upon each test. To identify the effect of the $\mathrm{ZnO}$ nanoparticles, experiments are performed on the dielectric without adding the $\mathrm{ZnO}$ nanoparticle.

Figure 4 shows the EDM device used in the experiments. For preventing possible precipitation of the nanoparticles in the dielectric, the dielectric material is circulated in the dielectric tank using a pump as is demonstrated in Figure 5. The final machined samples are demonstrated in Figure 6.

\section{Results And Discussion}

The effects of $\mathrm{ZnO}$ nanoparticles on MRR and surface roughness parameterts have been thoroughly investigated in roughing and finishing operations. Due to the importance of the surface quality after finishing operations, surface texture is also analyzed to correlate the $\mathrm{ZnO}$ mass addition to the generated surface texture.

\section{Investigation of MRR and surface roughness in the roughing operation}

The generated temperature in the tool-workpiece gap is larger due to the high electrical resistance and low thermal conductivity of the $\mathrm{ZnO}$ nanoparticles compare to other nanoparticles [33]. Many research works have mentioned that large sparks are divided into several small sparks when the nanoparticles of the dielectric with low electrical resistance and high thermal conductivity exist in the tool-workpiece gap. The mechanism of spark distribution in presence of nanoparticles is illustrated in Figure 7. The higher temperature field and the spark distribution lead to improvement of the surface roughness as well as the MRR [32]. The aim of this research is to study the effects of the $\mathrm{ZnO}$ addition on MRR, surface roughness, and surface texture of different material with different thermal conductivity. It is shown that high temperature developed upon the spark can lead to the deposition of the $\mathrm{ZnO}$ particles on the steel surface. In this study, the surface micro-cracks and the extent of $\mathrm{ZnO}$ deposition on different steel 
materials are also investigated. Different morphology of the holes in the generated surface texture are also discussed using analysis of the microscopic images acquired from the machined surfaces.

Figure 8 and Figure 9 illustrates the effects of adding 1-4g of the $\mathrm{ZnO}$ nanoparticle on the MRR and surface roughness of the roughing EDM prosses AISI 1045. Simultaneously investigation of those figures reveals that adding $4 \mathrm{~g} \mathrm{ZnO}$ nanoparticle leads to improving both the MRR and surface roughness parameters at same time. The MRR improvements are $10.71 \%$ and $5.88 \%$ at a peak current of $18 \mathrm{~A}$ and 24 A, respectively. According to Figure $9,11.3 \%$ and $9.7 \%$ improvements of the surface roughness are observed at a peak current of $18 \mathrm{~A}$ and $24 \mathrm{~A}$ (with $4 \mathrm{~g} / \mathrm{L}$ of the $\mathrm{ZnO}$ nanoparticles), respectively. Adding $2 \mathrm{~g}$ of the $\mathrm{ZnO}$ nanoparticle will also improve the surface roughness as much as $16.6 \%$. However, it must be mentioned that this will simultaneously lead to reducing the MRR.

Observations showed that, regardless of the peak current (18 A or $24 \mathrm{~A}$ ), the use of the $4 \mathrm{~g}$ of the $\mathrm{ZnO}$ nanoparticles in the roughing operation could both reduce the surface roughness and increase the MRR. As a result, adding this value of the $\mathrm{ZnO}$ nanoparticle can reduce the required cycle time of postprocessing operations after rough EDM of the workpieces.

Figure 10 shows the results of the rough EDM process of the AISI 4140, where the MRR is significantly improved by adding $4 \mathrm{~g}$ of the $\mathrm{ZnO}$ nanoparticles in compared to the conventional EDM. This figure illustrates that MRR can be enhance $50 \%$ at a peak current of $12 \mathrm{~A}, 33.33 \%$ at $18 \mathrm{~A}$, and $13 \%$ at 24 , as compared to the case of the conventional EDM. Investigation of the figure shows that the dielectric which includes $4 \mathrm{~g}$ of the $\mathrm{ZnO}$ nanoparticles at $18 \mathrm{~A}$ can establish the same MRR as that obtained by the conventional EDM process at $24 \mathrm{~A}$. Therefore, NPMEDM with $4 \mathrm{~g}$ of the $\mathrm{ZnO}$ nanoparticles can help to save the machining time. Figure 11 shows that adding $4 \mathrm{~g}$ of the $\mathrm{ZnO}$ nanoparticles at a peak current of 24 A reduces the surface roughness by $12.5 \%$. Simultaneously investigation of Figures 10 and 11 reveals that adding $4 \mathrm{~g} \mathrm{ZnO}$ nanoparticles improves the MRR and the surface roughness at the same time, reducing the cost of subsequent processes.

Figure 12 illustrates the MRR variations for different peak current and nanoparticle mass addition in rough EDM process of AISI D3. It can be inferred from Figure 12 that MRR increases significantly by adding $4 \mathrm{~g}$ of the $\mathrm{ZnO}$ nanoparticles at all of the considered peak currents, as compared to the conventional EDM. The MRR improvements are $25 \%, 14.28 \%, 45.45 \%$, and $18.75 \%$ at peak currents of 6 , 12,18 , and $24 \mathrm{~A}$, respectively. Similar to the previous case, the dielectric with $4 \mathrm{~g}$ of the $\mathrm{ZnO}$ nanoparticles at 18 A provides the same MRR as that of the conventional EDM at $24 \mathrm{~A}$, leading to energy saving. Although the MRR improvement is evident at all the investigated peak currents, the highest value takes place at $18 \mathrm{~A}$. The instability in the trends of Figure 8 and Figure 10 is due to the accumulation of chips in the machining gap. This phenomenon in EDM operation is called the unstable conditions.

The dispersion of the thermal energy of sparks on the surface of specimen leads to the reduction of the transferred thermal energy [13]. As a result, due to the decrease in the power density of electrical discharges and distribution of sparks, MRR is raised. In this situation, sparks energy and the volume of melted material in every spark are at the lower level and very small quantities of molten metal are 
expelled out of the melted crater in each spark, but all of the melted material is fast washed by the dielectric. This phenomenon simultaneously improves the surface roughness on the machined surface.

In NPMEDM of AISI D3, which includes $4 \mathrm{~g}$ of $\mathrm{ZnO}$, machining chips are easily removed from the gap and discharges are increased. As a result, the combination of $\mathrm{ZnO}$ and thermal conductivity of AISI D3 leads to generate the wider and deeper holes in this material while in AISI 1045 and AISI 4140 machining the wider and shallow holes are generated. According to the results, for AISI 1045 and AISI 4140 workpieces, increasing the peak current generally improves the MRR. However, increasing peak current decreases surface roughness only for the case which includes $4 \mathrm{~g}$ of the $\mathrm{ZnO}$ nanoparticle in the dielectric. This behaviour has been further investigated using the analysis of the images acquired from the surface texture in the next section.

According to some references (e.g., [36]), the relationship between the decrease in the electrical resistance within the tool-workpiece gap and the increase in the electrical discharge energy is described. The different MRR during EDM process of various steel materials can be related to different thermal conductivity of the material [41]. Since the workpiece surface temperature increases up to $1000^{\circ} \mathrm{C}$ at the spark time [41], the thermal conductivity of the steel at this elevated temperature must be considered. Table 3 presents the thermal conductivities and densities of the utilized steel alloys in this study. Simultaneous investigation of the variation of the MRR (at peak current 18A and 24A) and the thermal conductivity of the steel material reveals that the thermal conductivity can be considered as the main cause of increasing MRR in the experiment. In contrast to the Ref. [41], no significant correlation is observed between the MRR and the material density.

Since the optimal outcomes of the EDM process in the roughing and finishing operations could be obtained by adding $4 \mathrm{~g}$ of the $\mathrm{ZnO}$ nanoparticles, the surface texture developed upon nano powder-mixed electrical discharge machining (NPMEDM) and conventional EDM was evaluated in the following.

\section{Table 3. The thermodynamic and physical properties of steels}

\begin{tabular}{|lll|}
\hline Thermal conductivity coefficient $(\mathrm{W} / \mathrm{mk})$ at $1000^{\circ} \mathrm{C}$ & Density $(\mathrm{kg} / \mathrm{m} 3)$ at $25^{\circ} \mathrm{C}$ & Material \\
\hline 22.61 & 7870 & AISI 1045 \\
\hline 27.4 & 7850 & AISI 4140 \\
\hline 28.5 & 7670 & AISI D3 \\
\hline
\end{tabular}

\section{The surface texture of roughing operation}

According to Figures 8 and 9 for AISI 1045 and also Figures 10 and 11 for AISI 4140, improved MRR and surface roughness are evident at higher peak currents when $4 \mathrm{~g}$ of the $\mathrm{ZnO}$ nanoparticles is added to the dielectric. On the other hand, it can be inferred from Figures 12 and 13 that although adding $4 \mathrm{~g}$ of the $\mathrm{ZnO}$ nanoparticle improves the MRR for the EDM process of AISI D3 at higher peak currents, it increases the surface roughness parameter. This can lead to the conclusion that the holes generated by NPMEDM 
on the AISI D3 are deeper compared to that of the conventional EDM. In order to confirm this conclusion and investigate the crack formation on the surface, macroscopic investigations were performed on the machined surfaces. For this purpose, macroscopic images were acquired at 100X magnification using a Salran IMM-420 microscope.

As is illustrated by Figures 14 through 16, the increase in the nanoparticle mass in the dielectric at peak currents of $18 \mathrm{~A}$ and $24 \mathrm{~A}$ results in the significant cracks development on walls of the generated holes (as compared to the conventional EDM), which can be the main reason for the higher MRR. The number of the cracks as well as their size is so large (e.g., Figures 15A and 15B for AISI 4140) that they can damage the hole wall. Furthermore, considering the surfaces created at peak currents of $6 \mathrm{~A}$ and $12 \mathrm{~A}$ (Figures 15C and 15D), it is evident that the surface produced with the NPMEDM hosts almost the same number of cracks as that seen on the surface produced by the conventional EDM. Because of this, the two dielectrics exhibits almost the same performance in terms of the MRR. On the other hand, the crack formation is clearly detectable in Figures $15 \mathrm{~A}-15 \mathrm{C}$ and also $16 \mathrm{~A}-16 \mathrm{C}$. The crack formation is also evident in the conventional EDM, but under similar operating conditions (e.g., Figures $16 \mathrm{~F}$ and 16B), the cracks development in the NPMEDM are significantly larger and more abundant than those of the conventional EDM. Therefore, the crack formation can be another reason behind the improved MRR with the NPMEDM compared to the conventional EDM. Finally, it should be noted that the higher thermal conductivity of the dielectric in the NPMEDM leads to the formation of more cracks on the workpiece surface. Moreover, by increasing the dielectric temperature due to the generated heat flux and the thermal conductivity of different materials, temperature difference between the melted material and the dielectric appears; hence higher solidification shrinkage causes more thermal stresses. Under this condition, the number of micro cracks is increased $[42,43]$. The simultaneous consideration of Figures $14 \mathrm{~A}, 15 \mathrm{~A}$ and $16 \mathrm{~A}$ as well as 14B, $15 \mathrm{~B}$ and $16 \mathrm{~B}$ illustrates that higher thermal conductivity of the workpiece (See Table3) can affect increasing the number of the cracks and enhancing MRR under same machining parameters.

In order to analyse the different surface roughness acquired for different conditions, the depths of the holes generated with and without the $\mathrm{ZnO}$ nanoparticles $(4 \mathrm{~g})$ at peak currents of $18 \mathrm{~A}$ and $24 \mathrm{~A}$ are investigated. Due to the focal length and blurred background of the holes in Figures $14 \mathrm{E}$ and $14 \mathrm{~F}$ compared to $14 \mathrm{~A}$ and $14 \mathrm{~B}$, it can be inferred that deeper holes exists for the case of EDM without ZnO nanoparticles. As is evident in the images, the features within a particular distance from the lens of the microscope are sharp, while the sharpness reduces as the feature gets farther from the lens. Thus, it is expected that surface roughness improves in NPMEDM because of shallower depth of the holes compared to the conventional EDM. Similar conditions are observed when comparing Figure 15A to Figure $15 \mathrm{E}$ and also Figure 15B to Figure 15F. But an opposite performance is observed in Figures 16A and $16 \mathrm{E}$ and also Figures $16 \mathrm{~B}$ and $16 \mathrm{~F}$. Furthermore, Figures $16 \mathrm{~A}$ and $16 \mathrm{~B}$ show that many cracks have developed on the walls of the holes, so the material removal is performed in parallel to the surface direction instead of the normal to surface direction. This issue justifies the improvement of MRR and higher surface roughness of AISI D3 workpiece as compared to the other materials. Additionally, increasing the thermal conductivity of dielectric by adding the $\mathrm{ZnO}$ nanoparticle mitigates the plasma heat flux towards the electrodes [13], which leads to the formation of holes, peaks and valleys with 
smaller sizes. Especially, this issue is quite obvious by comparing Figures 14D with 14H, Figure 15D with $15 \mathrm{H}$ and Figure16D with $16 \mathrm{H}$.

\section{Investigation of MRR and surface roughness in the finishing operation}

In the previous section, the optimal operating conditions are discussed to acquire the best MRR and surface roughness values at different high peak currents of roughing operation. This section aims to understand the effect of the $\mathrm{ZnO}$ nanoparticles on the performance of the finishing operation with peak current of $6 \mathrm{~A}$. The finishing operation is an important process because it defines the final state of the machined. The improved surface quality and the deposition of the ZnO nanoparticles on the workpiece surface after NPMEDM finishing process, will enhance the performance, service factor, and quality of the final product.

In the finishing operation, the peak current of 6A with different mass values of ZnO nanoparticles (from $1 \mathrm{~g}$ to $4 \mathrm{~g}$ ) are considered. As it can be observed in Figures 17 through 19, for AISI 1045, 16.66\% surface roughness improvement is achieved using $2 \mathrm{~g}$ of the $\mathrm{ZnO}$ nanoparticles. However, adding any mass level of ZnO nanoparticles improves the surface roughness of AISI 4140 and AISI D3 workpieces. The highest

surface roughness improvement is respectively observed as $29.41 \%$ and $56.25 \%$ in AISI 4140 and AISI D3 by adding $3 \mathrm{~g}$ of the $\mathrm{ZnO}$ nanoparticles. Considering both MRR and the surface roughness (Figures 1719), it can be deduced that for the AISI D3, better surface quality and higher MRR at same time can be achieved by adding $4 \mathrm{~g}$ of $\mathrm{ZnO}$ nanoparticles, which is a significant finding.

\section{Investigation of surface texture in finishing operation}

In order to inspect the surface texture and the deposition of the $\mathrm{ZnO}$ nanoparticles on the machined surface, the samples are initially cleaned by ultrasonic waves at $1500 \mathrm{~W}$ for 8 hours, to remove the weak couplings between the ZnO nanoparticles and the surface. Next, the SEM and DLS assessments are carried out on to determine the mass percentage of the $\mathrm{ZnO}$ nanoparticles on the sample surfaces. LeQ $1450 \mathrm{Vp}$ SEM machine is used in this research work. Figures 20 through 22 present the images acquired from the samples which are manufactured using NPMEDM with $4 \mathrm{~g}$ of the ZnO nanoparticles at the peak current of $6 \mathrm{~A}$.

An important observation from the images is reducing the number and width of the surface cracks when $4 \mathrm{~g}$ of the nanoparticles are added to the steel materials. The deposition of the nanoparticles on the machined surfaces and the reduction of the surface crack formation can significantly improve the wear resistance of the surface. On the other hand, it can be observed that the surface texture of AISI 1045 and AISI 4140 have greater number of holes compared to the AISI D3. It can be useful to prevent the wear of the material by keeping some lubricant in cracks and holes of AISI 1045 and AISI 4140. The deposition of $\mathrm{ZnO}$ on the surface of these materials could increase the wear resistance of these steel materials. 
In order to measure the amount of the deposited $\mathrm{ZnO}$ nanoparticles on the steel surfaces, DLS analyses are performed and the median of the results of 10 images is reported as the percentage of the weight of deposited $\mathrm{ZnO}$ nanoparticles. Figure 23 shows the results of the DLS analysis for the deposition of the $\mathrm{ZnO}$ nanoparticles on the steel surface when $4 \mathrm{~g}$ of the nanoparticles are added to the dielectric. The results are obtained at an accelerated voltage of $15 \mathrm{kV}$ and beam current of $470,000 \mathrm{nA}$. Figure 24 shows the spectra corresponding to the material presented in Figure 23A.

Investigation of SEM images and DLS analysis indicates that the percent weight of deposited ZnO nanoparticles is the highest for AISI 4140 followed by AISI 1045 and AISI D3. Figure 25 shows the changes in the percentage of the $\mathrm{ZnO}$ nanoparticles mass deposited of on various steel materials. Accordingly, it is found that, when $4 \mathrm{~g}$ of $\mathrm{ZnO}$ nanoparticles is added to the dielectric, the percentage of the ZnO nanoparticles mass deposited on AISI 1045 and AISI D3 surfaces are $21.7 \%$ and $56.52 \%$ higher than that on AISI 4140, respectively.

\section{Conclusion}

In this paper, the EDM process of different steel materials and the effects of adding zinc oxide ( $\mathrm{ZnO}$ ) nanoparticles to the dielectric (kerosene) are investigated. Different masses of the nanoparticles and peak currents are utilized to investigate the MRR, the surface roughness, and the surface texture of the product. According to the results, the use of $4 \mathrm{~g} / \mathrm{L}$ nanoparticles can improve the material removal rate (MRR) for the AISI 1045, AISI 4140, and AISI D3. It is observed that the trend of the MRR improves when the workpiece has higher thermal conductivity. This improvement is due to the higher number of surface cracks by increasing the thermal conductivity of the material.

The significant improvements are observed with AISI 4140 and AISI D3 steel materials. The maximum improvements of the MRR are $50 \%, 45.55 \%$, and $10.71 \%$ for AISI 4140 , and AISI D3, and the AISI 1045, respectively. The analysis of the microscopic images showed that the increase in the MRR of AISID3 is due to the increase in the surface crack developments by incorporating the $\mathrm{ZnO}$ nanoparticles which leads to the higher depth of the holes and the more generated cracks on walls.

On the other hand, adding 2, 3, and 4 grams of the $\mathrm{ZnO}$ nanoparticles into the dielectric for machining of the AISI 1045, AISI 4140, and AISI D3 steel materials improves the surface roughness quality by $20 \%$, $30 \%$, and $60 \%$, respectively, as compared to the results of the conventional EDM. By investigating the improvements obtained in different steel materials, it can be concluded that the addition of the $\mathrm{ZnO}$ nanoparticles cannot significantly improve the results with the AISI 1045 steel. However, significant improvements are obtained in the AISI 4140 and AISI D3 during both roughing and finishing operations. It should be noted that these improvements achieve by a nanoparticle with low thermal conductivity and high electrical resistance compared to the conventional nanoparticle. Therefore, it is concluded that the thermal conductivity of nanoparticle, the thermal conductivity of the workpiece, and the electrical resistance of nanoparticle are three parameters that should be taken in account for evaluating the performance of a nanoparticle. 
A major advantage of the utilizing nanoparticle (when $4 \mathrm{~g} / \mathrm{L}$ is added) is its simultaneously improvements on both the MRR and surface roughness of the AISI D3 in finishing operation which can contribute to lower production cost and higher quality of the manufactured product.

The most important observation of this work is the deposition of the $\mathrm{ZnO}$ nanoparticles on the surface of the final product. This phenomenon can be utilized to enhance the efficiency of the products in terms of higher wear resistance, lower friction coefficient, better surface quality and hence enhance the lifetime of the parts produced through this methodology. This phenomenon happens due to the high temperature of the plasma channel at spark zone, the resultant melting, and the incorporation of the $\mathrm{ZnO}$ nanoparticles into the existing steel structures. The results show that the maximum percentage of the $\mathrm{ZnO}$ nanoparticles deposition (at $4 \mathrm{~g}$ ) happens for AISI D3 followed by AISI 1045 and AISI 4140.

\section{Declarations}

- The authors have no relevant financial or non-financial interests to disclose.

- The authors have no conflicts of interest to declare that are relevant to the content of this article.

- All authors certify that they have no affiliations with or involvement in any organization or entity with any financial interest or non-financial interest in the subject matter or materials discussed in this manuscript.

- The authors have no financial or proprietary interests in any material discussed in this article.

\section{Funding}

The authors did not receive support from any organization for the submitted work. Also, the authors declare they have no financial interests. Therefore, the authors have no relevant financial or non-financial interests to disclose.

\section{Conflicts of interest/Competing interests}

There are not any Conflicts of interest and Competing interests about the presented results in this paper. All results are based on laboratory data and based on common statistical criteria in the scientific articles.

\section{Availability of data and material}

All of data and material are presented in figures

\section{Code availability}

Not applicable 


\section{References}

[1] Ekmekci B, Tekkaya AE, Erden A (2007) A semi- empirical approach for residual stresses in electric discharge machining (EDM). International Journal of Machine Tools and Manufacture 47; 1214-1228. https://doi.org/ 10.1016/j.jjmachtools.2005.07.020

[2] Kunieda M, Lauwers B, Rajurkar KP, Schumacher BM (2005) Advancing EDM through fundamental insight into the process. CIRP Annals Manufacturing Technology 54:64-87. https://doi.org/10.1016/s0007-8506(07)60020-1

[3] Zhang G, Guo J, Ming W, Huang Y, Shao X, Zhang Z (2014) Study of the machining process of nanoelectrical discharge machining based on combined atomistic-continuum modelling method. Applied Surface Science 290:359-367. https://doi.org/ 10.1016/j.apsusc.2013.11.084

[4] Chaudhury P, Samantaray S (2017) Role of Carbon Nano Tubes in Surface Modification on Electrical Discharge Machining -A Review. Materials Today: Proceedings 4:4079-4088. https://doi.org/ 10.1016/j.matpr.2017.02.311

[5] Yunus KM, Sudhakar RP, Pabla BS (2020) Powder mixed electrical discharge machining (PM-EDM): A methodological review. Materials Today Proceedings https://doi.org/ 10.1016/j.matpr.2020.10.122

[6] Zhang Y, Liu Y, Shen Y, Ji R, Li Z, Zheng C (2014) Investigation on the Influence of the Dielectrics on the Material Removal Characteristics of EDM. Journal of Materials Processing Technology 214:1052-1061 https://doi.org/10.1016/j.jmatprotec.2013.12.012

[7] Kumar A, Mandal A, Dixit A. R, Kumar Das A (2018) Performance Evaluation of $\mathrm{Al}_{2} \mathrm{O}_{3}$ Nano PowderMixed Dielectric for Electric Discharge Machining of Inconel 825. Materials and Manufacturing Processes 33:1-26. https://doi.org/10.1080/10426914.2017.1376081

[8] Kuldeep O, Garg RK, Singh RK (2011) Experimental investigation and modeling of PMEDM process with chromium powder suspended dielectric. International Journal of Applied Science and Engineering 9(2):65-81.

[9] Jawahar M, Sridhar Reddy Ch, Srinivas Ch (2019) A review of performance optimization and current research in PMEDM. Materials today 19(2):742-747. https://doi.org/ 10.1016/j.matpr.2019.08.122.

[10] Tan PC, Yeo SH, Tan YV (2008) Effects of nano-sized powder additives in micro-electrical discharge machining. International Journal of Precision Engineering and Manufacturing 9(3): 22-26.

[11] Kumar H (2014) Development of mirror like surface characteristics using nano powder mixed electric discharge machining (NPMEDM). International Journal of Advanced Manufacturing Technology 76:105113. https://doi. org/10.1007/s00170-014-5965-6. 
[12] Kolli M, Kumar A (2017) Surfactant and graphite powder-assisted electrical discharge Machining of titanium alloy. Proceedings of the Institution of Mechanical Engineers Part B: Journal of Engineering Manufacture 231:641-657. https://doi.org/ 10.1177/0954405415579019

[13] Shabgard M, Khosrozadeh B (2017) Investigation of carbon nanotube added dielectric on the surface characteristics and machining performance of Ti-6Al-4V alloy in EDM process. Journal of Manufacturing Processes 25:212-219. https://doi.org/ 10.1016/j.jmapro.2016.11.016

[14] Mohal S, Kumar H (2017) Study on the Multiwalled Carbon Nano tube Mixed EDM of AISiCp Metal Matrix Composite. Materials Today: Proceedings 4:3987-3993. Https://doi.org/ 10.1016/j.matpr.2017.02.299

[15] Assarzadeh S; Ghoreishi M (2013) A dual response surface desirability approach to process modeling and optimization of $\mathrm{Al}_{2} \mathrm{O}_{3}$ powder-mixed electrical discharge machining (PMEDM) parameters. International Journal of Advanced Manufacturing Technology 64:1459-1477. doi : 10 . 1007 / s00170 012-4115-2

[16] Furutani K, Sato H, Suzuki M (2009) Influence of Electrical Conditions on Performance of Electrical Discharge Machining with Powder Suspended in Working Oil for Titanium Carbide Deposition Process. International Journal Of Advanced Manufacturing Technology 40 (11):1093-1101. https://doi.org/ $10.1007 /$ s00170-008-1420-x

[17] Peças P, Henriques E (2008) Effect of the powder concentration and dielectric flow in the surface morphology in electrical discharge machining with powder-mixed dielectric (PMD-EDM). International Journal Of Advanced Manufacturing Technology 37:1120-1132. https://doi.org/ 10.1007/s00170-0071061-5

[18]. SinghAK, Kumar S, Singh VP (2015) Effect of the addition of conductive powder in dielectric on the surface properties of super alloy super co 605 by EDM process. International Journal Of Advanced Manufacturing Technology 77:99-106. https://doi.org/10.1007/s00170-014-6433-z

[19] Prihandana GS, Mahardika M, Hamdi M, Wong YS Mitsui K (2011) Accuracy improvement in nanographite powder-suspended dielectric fluid for micro-electrical discharge machining processes International Journal Of Advanced Manufacturing Technology 56:143-149. https://doi.org/ 10.1007/s00170-011-3152-6

[20] Bhattacharya A, Batish A, Singh G Singla VK (2012) Optimal parameter settings for rough and finish machining of die steels in powder-mixed EDM. International Journal Of Advanced Manufacturing Technology 61:537-548. https://doi.org/ 10.1007/s00170-011-3716-5

[21] Bhattacharya A, Batish A, Kumar N (2013) Surface characterization and material migration during surface modification of die steels with silicon graphite and tungsten powder in EDM process. Journal of Mechanical Science and Technology 27:133-140. https://doi.org/10.1007/s12206-012-0883-8 
[22] Hosni NAJ, Lajis MA, Idris MR (2018) Modeling and Optimization of Chromium Powder Mixed EDM Parameter Effect Over the Surface Characteristics by Response Surface Methodology Approach. International Journal of Engineering Materials and Manufacture 3(2):78-86. https://doi.org/ 10.26776/IJEMM.03.02.2018.02

[23] Guua YH, Hocheng H, Choua CY, Denga CS (2003) Effect of electrical discharge machining on surface characteristics and machining damage of AISI D2 tool steel. Materials Science and Engineering 358:37-43. https://doi.org/ 10.1016/S0921-5093(03)00272-7

[24] Prabhu S, Vinayagam BK (2011) AFM surface investigation of Inconel 825 with multi wall carbon nano tube in electrical discharge machining process using Taguchi analysis. Materials Science Archives of Civil and Mechanical Engineering 11(1):149-170. https://doi.org/ 10.1016/S1644-9665(12)60180-0

[25] Prabhu S, Vinayagam BK (2013) AFM nano analysis of inconel 825 with single wall carbon nano tube in die sinking EDM process using taguchi analysis. Arabian Journal for Science and Engineering 38:1599-1613. https://doi.org/ 10.1007/s13369-012-0348-5

[26] Sari MM, Noordin MY, Brusa E (2013) Role of multi-wall carbon nanotubes on the main parameters of the electrical discharge machining (EDM) process. International Journal Of Advanced Manufacturing Technology 68:1095-102.https://doi.org/ 10.1007/s00170-013-4901-5

[27] Mai C, Hocheng H, Huang S (2011) Advantages of carbon nano tubes in electrical discharge machining. International Journal of Advance Manufacturing Technology 59:111-117. https://doi.org/ $10.1007 / \mathrm{s} 00170-011-3476-2$

[28] Kumar H (2015) Development of mirror like surface characteristics using nano powder mixed electric discharge machining (NPMEDM). International Journal Of Advanced Manufacturing Technology 76(14):105-113. https://doi.org/ 10.1007/s00170-014-5965-6

[29] Kumar A, Mandal A, Dixit A R, Kumar Das A, Kumar S, Ranjan R (2019) Comparison in the performance of EDM and NPMEDM using $\mathrm{Al}_{2} \mathrm{O}_{3}$ nanopowder as an impurity in DI water dielectric. The International Journal of Advanced Manufacturing Technology 100:1327-1339. https://doi.org/10.1007/s00170-018-c-z.

[30] Saravanakumar A, Santarao K, Nandin G (2018) Influence of Alumina Nano Powder Mixed Dielectric Fluid In Electric Spark Machining Of AISI D3 Steel. International Journal of Mechanical and Production Engineering Research and Development 8(2):1257-1264. 10.24247/ijmperdapr2018165

[31] Kavadea M V, Mohiteb SS, Unaunec D R (2019) Application of metal powder to improve metal removal rate in Electric Discharge Machining. Materials Today: Proceedings 16:398-404. https://doi.org/ 10.1016/j.matpr.2019.05.107 
[32] Abhishek A, Sunil Sh (2015) Effect Of Chromium Powder Mixed Dielectric on Performance Characteristics of AISI D2 Die Steel Using EDM. International Journal of Research in Engineering And Technology 4(1):232-246.

[33] Fattahi H: Pak A (2018) Investigation of Ultrasonic Assisted Electro Discharge Machining with $\mathrm{Al}_{2} \mathrm{O}_{3}$ TiO and ZnO Nano-Powder. Amirkabir Journal of Mechanical Enineering 50(3):177-180. https://doi.org/ 10.22060/mej.2017.11875.5205

[34] Hernandez Battez A, Gonzalez R, Viescaetal JL (2018) CuO ZrO2 and ZnO nanoparticles as anti-wear additive in oil lubricants. Wear 265(3-4):422-428. Https://doi.org/ 10.1016/j.wear.2007.11.013

[35] Joshi A Y, Joshi A Y (2019) A systematic review on powder mixed electrical discharge machining. Heliyon 5: 1-12. https://doi.org/10.1016/ j.heliyon.2019.e02963.

[36] Choudhary KK (2012) Analysis of temperature-dependent electrical resistivity of ZnO nano-structures. Journal of Physics and Chemistry of Solids 73:460-464. https://doi.org/ 10.1016/j.jpcs.2011.11.020

[37] Olorunyolemi T, Birnboim A, Carmel Y ; Jr OW ; Lloyd I K (2002) Thermal Conductivity of Zinc Oxide: From Green to Sintered State. Journal of the American Ceramic Society 85(5):1249-53. https://doi.org/ 10.1111/j.1151-2916.2002.tb00253.x

[38] Khoshhesab Z M, Sarfaraz M ; Asadabad M A (2011) Preparation of ZnO Nanostructures by Chemical Precipitation Method synthesis and Reactivity in Inorganic Metal-Organic and Nano-Metal. Chemistry 41(7):814-819 https://doi.org/10.1080/15533174.2011.591308

[39] Akhtar M J, Ahamed M, Kumar S, Khan MA M, Ahmad J, SAlrokayan A (2012) Zinc oxide nanoparticles selectively induce apoptosis in human cancer cells through reactive oxygen species. International Journal of Nanomedicine 7:845-857. https://doi.org/10.2147/IJN.S29129

[40] Ji R, Liu Y, Diao R, Xu C, Li X, Yonghong Liu Cai B, Zhang Y (2014) Influence of Electrical Resistivity and Machining Parameters on Electrical Discharge Machining Performance of Engineering Ceramics. PLoS ONE 9(11):1-9. https://doi.org/10.1371/journal.pone.0110775

[41] Gu L, Zhu Y, He G, Farhadi A, Zhao W (2019) Coupled numerical simulation of arc plasma channel evolution and discharge crater formation in arc discharge machining. International Journal of Heat and Mass Transfer 135:674-684. https://doi.org/ 10.1016/j.ijheatmasstransfer.2019.02.022

[42] Guu YH, Mai CC, Hocheng H (2008) Applications of carbon nanotubes in nontraditional machining and microscopy In: Mishra AK editor Applications of carbon nanotubes. Nova Science Publishers 11126.

[43] Khan AA, Ndaliman MB, Zain ZM, Jamaludin MF, Patthi U, (2012) Surface modification using electric discharge machining (EDM) with powder addition. Applied Mechanics and Materials 110-116:725-33 
Figures

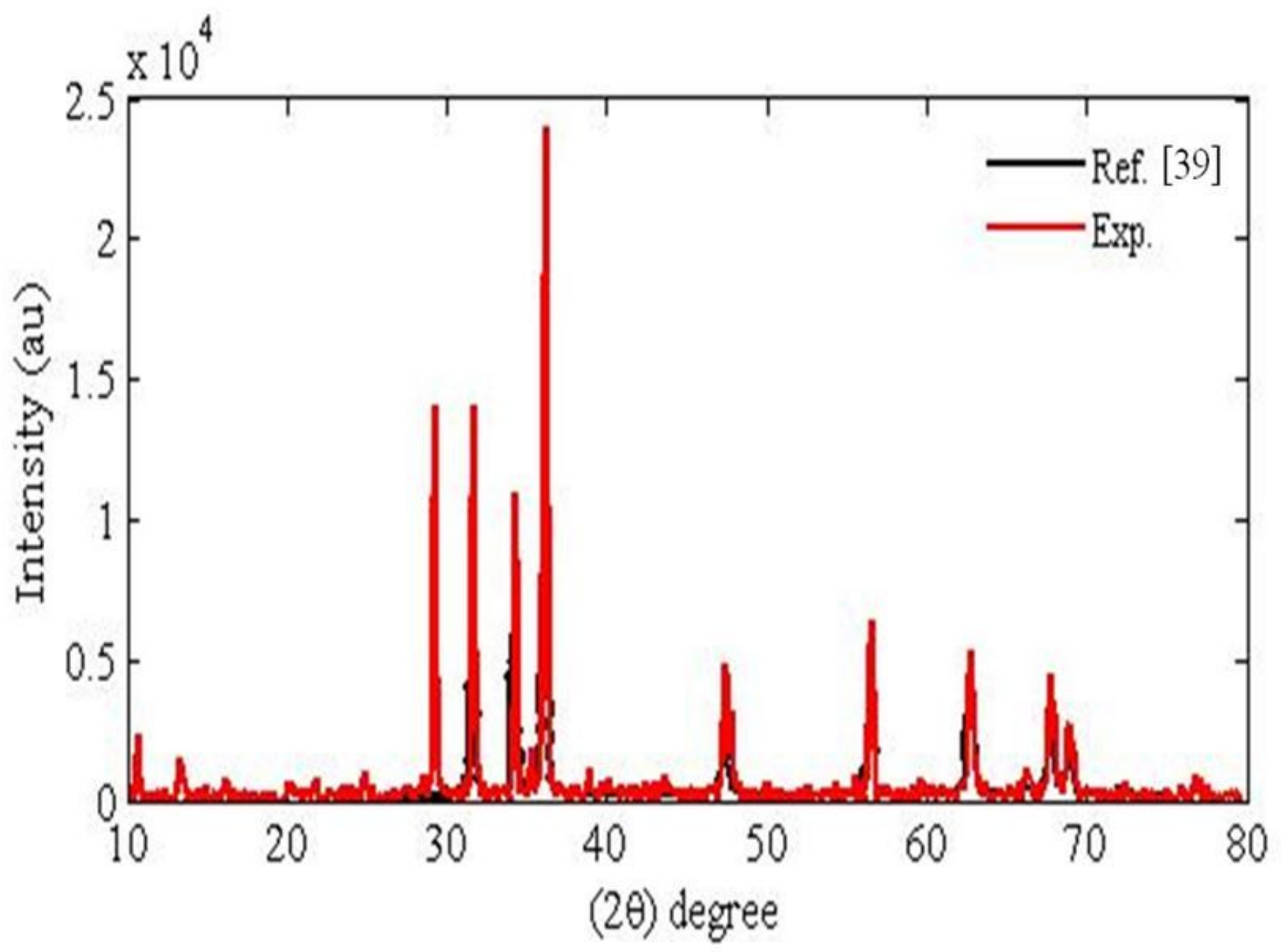

Figure 1

The XRD of the ZnO nanoparticles 


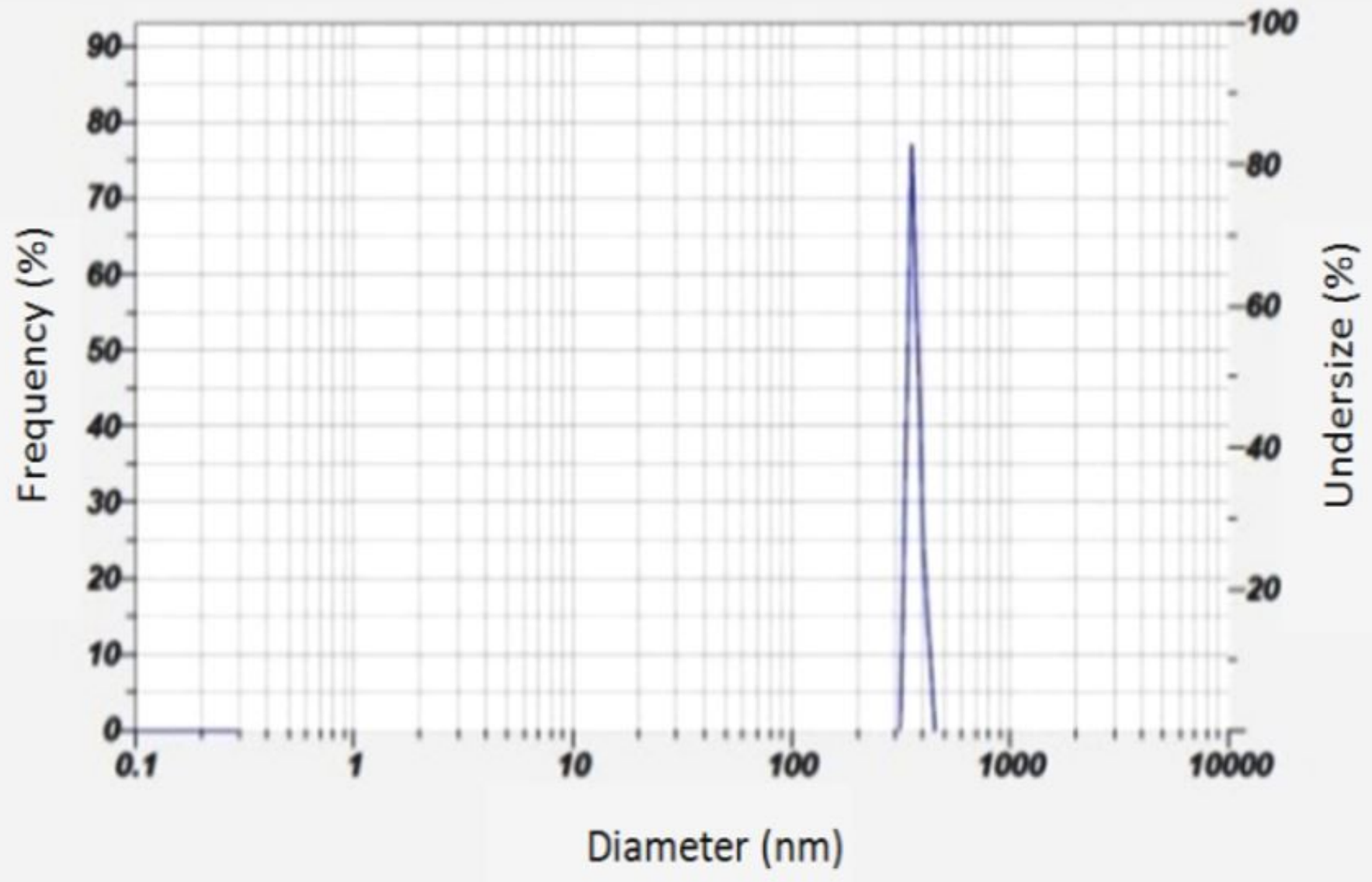

Figure 2

Nanoparticle size by DLS tests 


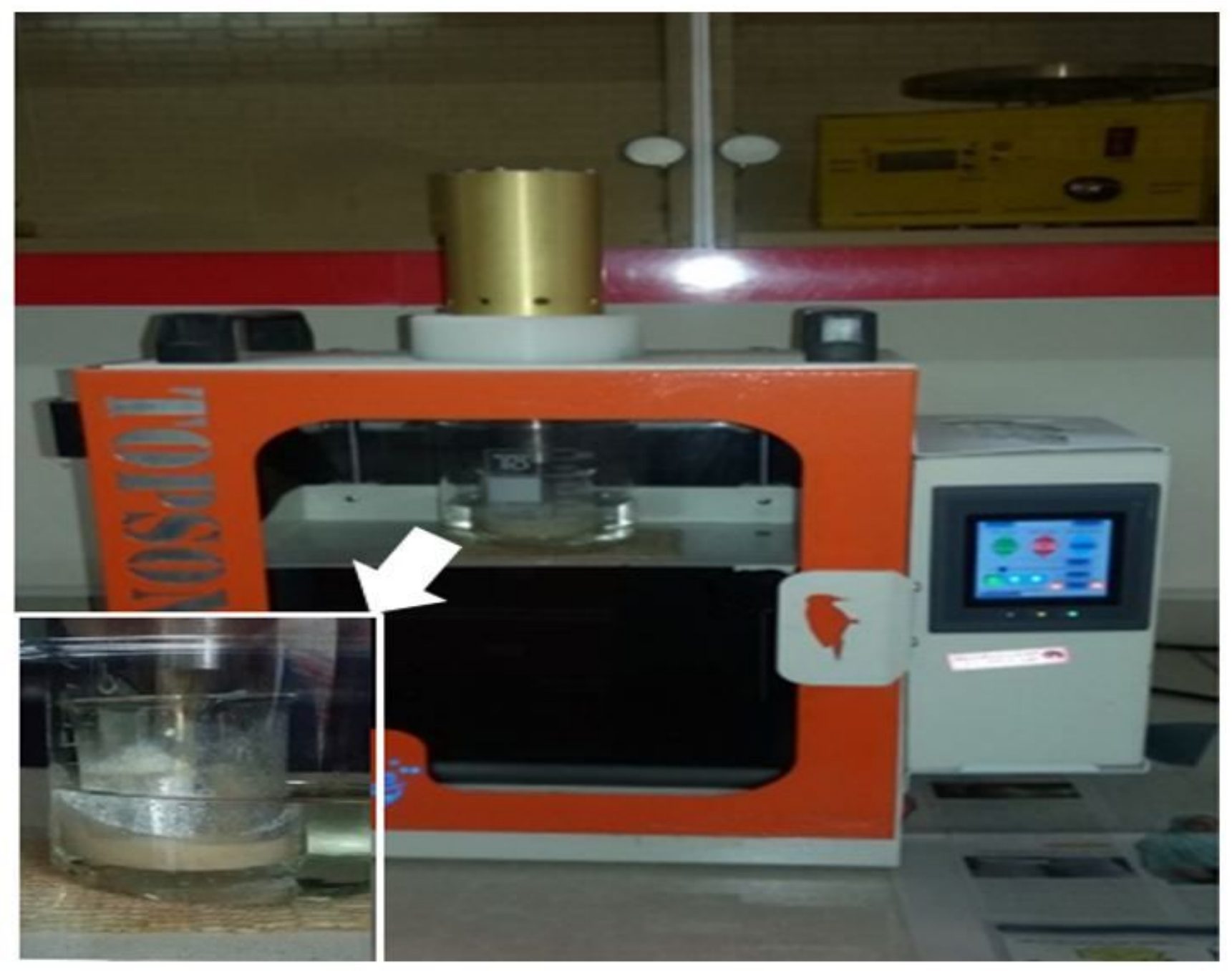

Figure 3

Preparing the dielectric containing the nanoparticle 


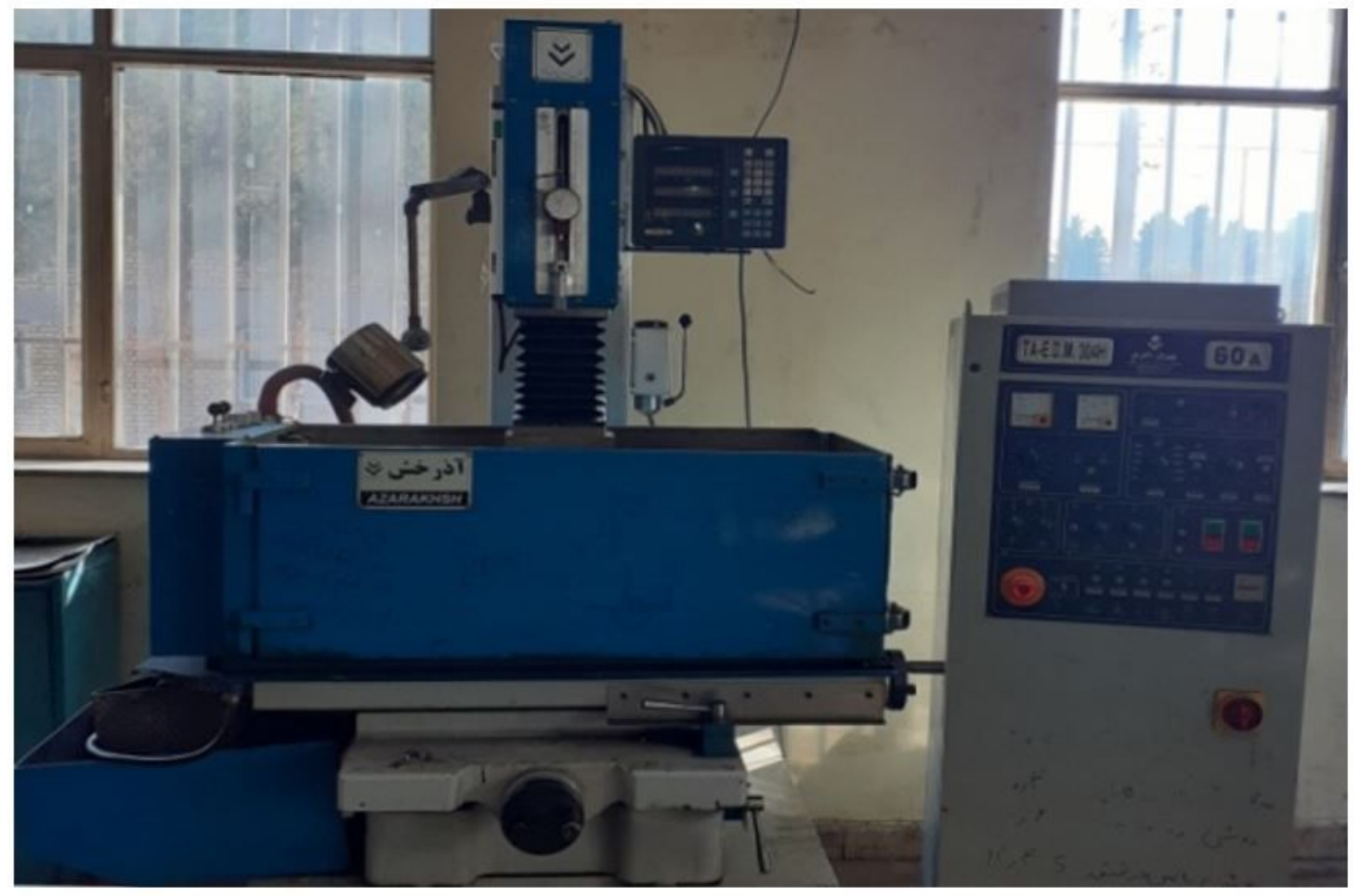

Figure 4

The experimental setup- the EDM machine 


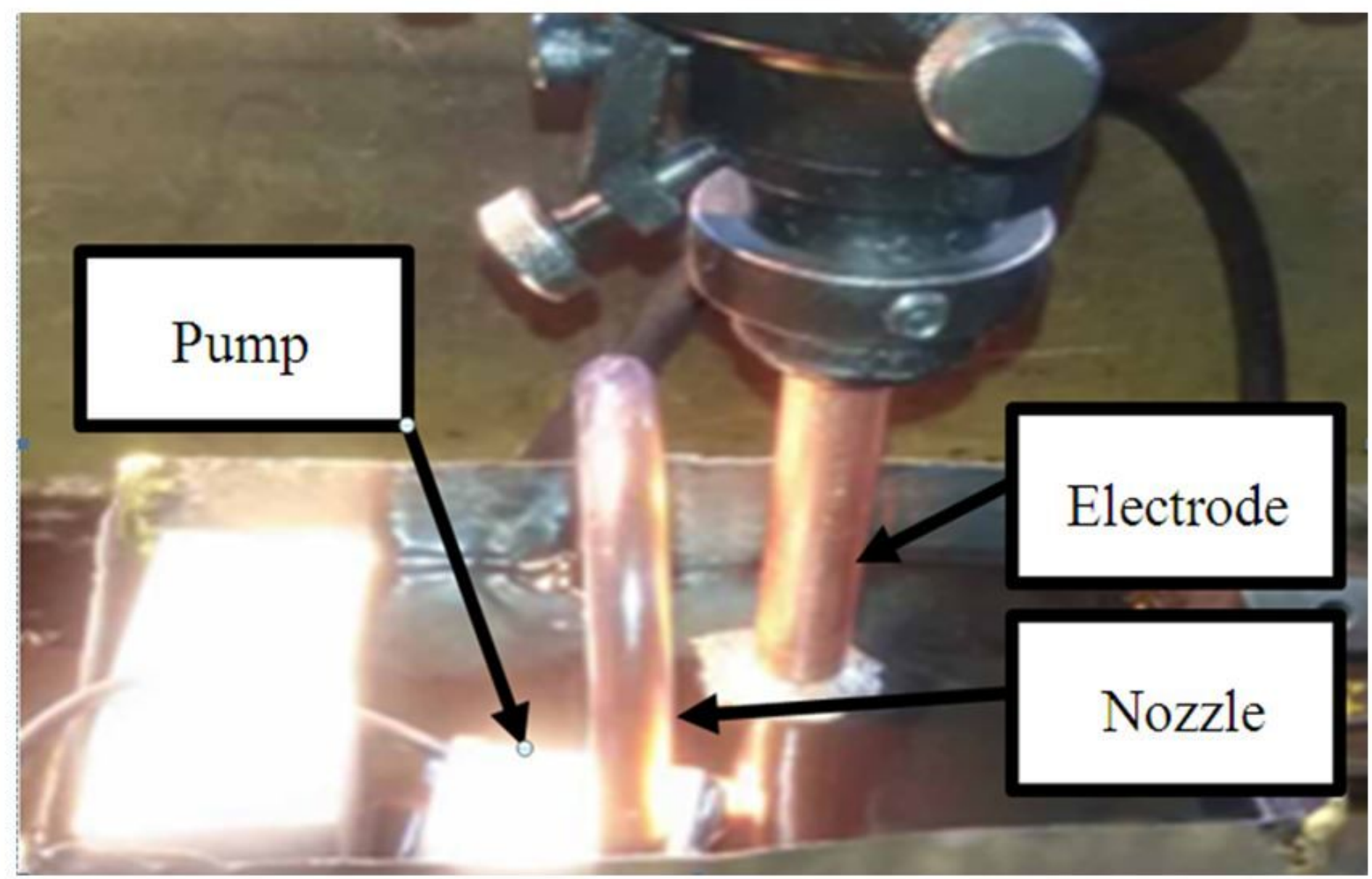

Figure 5

The closed-loop is made for the EDM process 


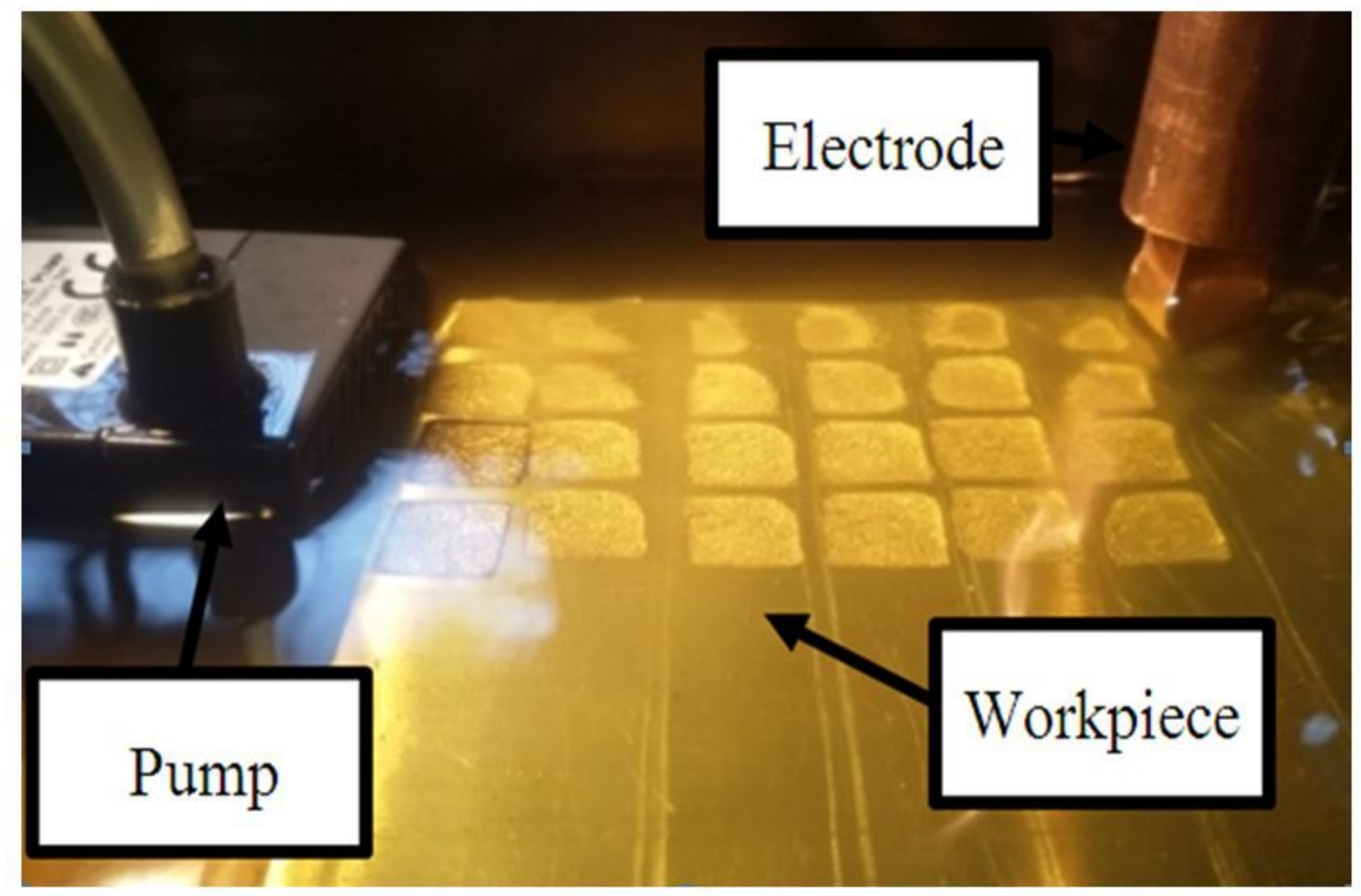

Figure 6

The machined samples by the EDM process

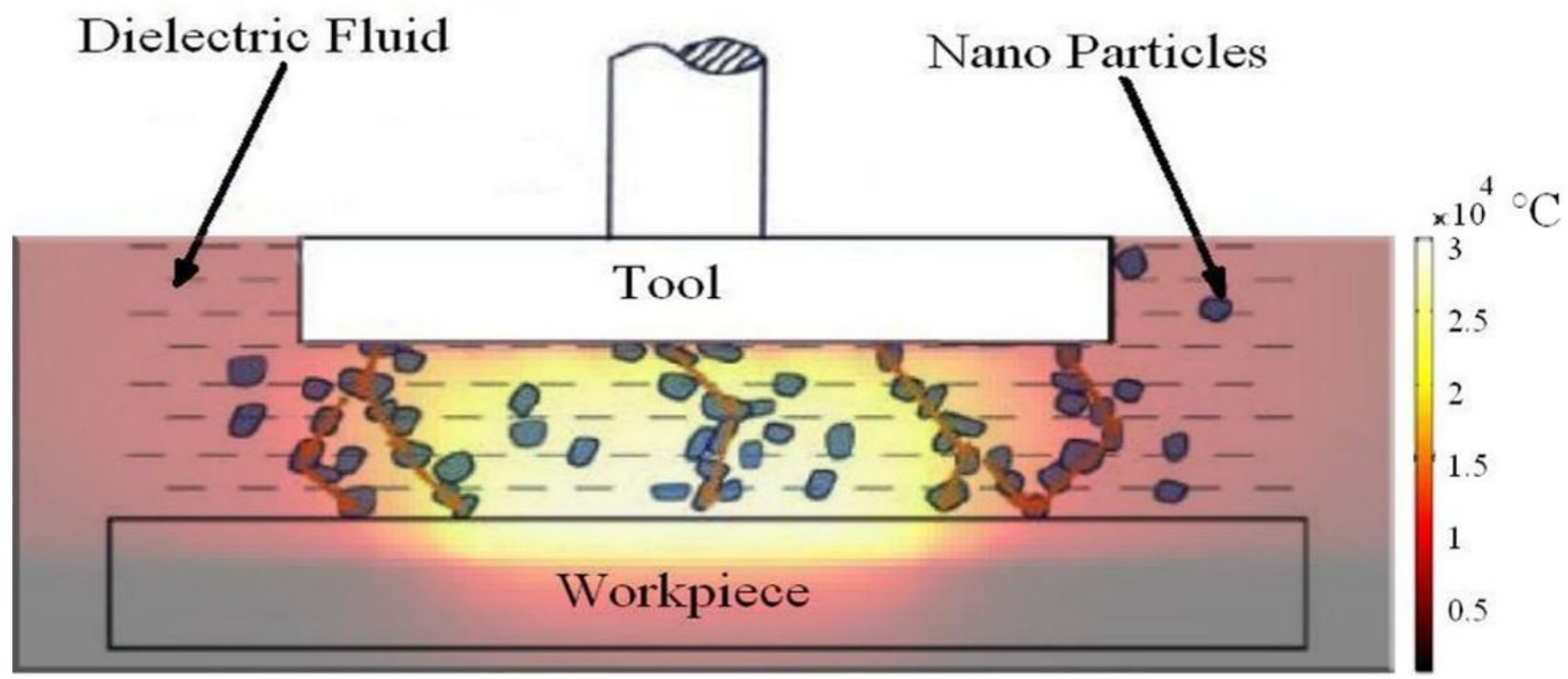

Figure 7 
The effect of nanoparticles in sparks distribution

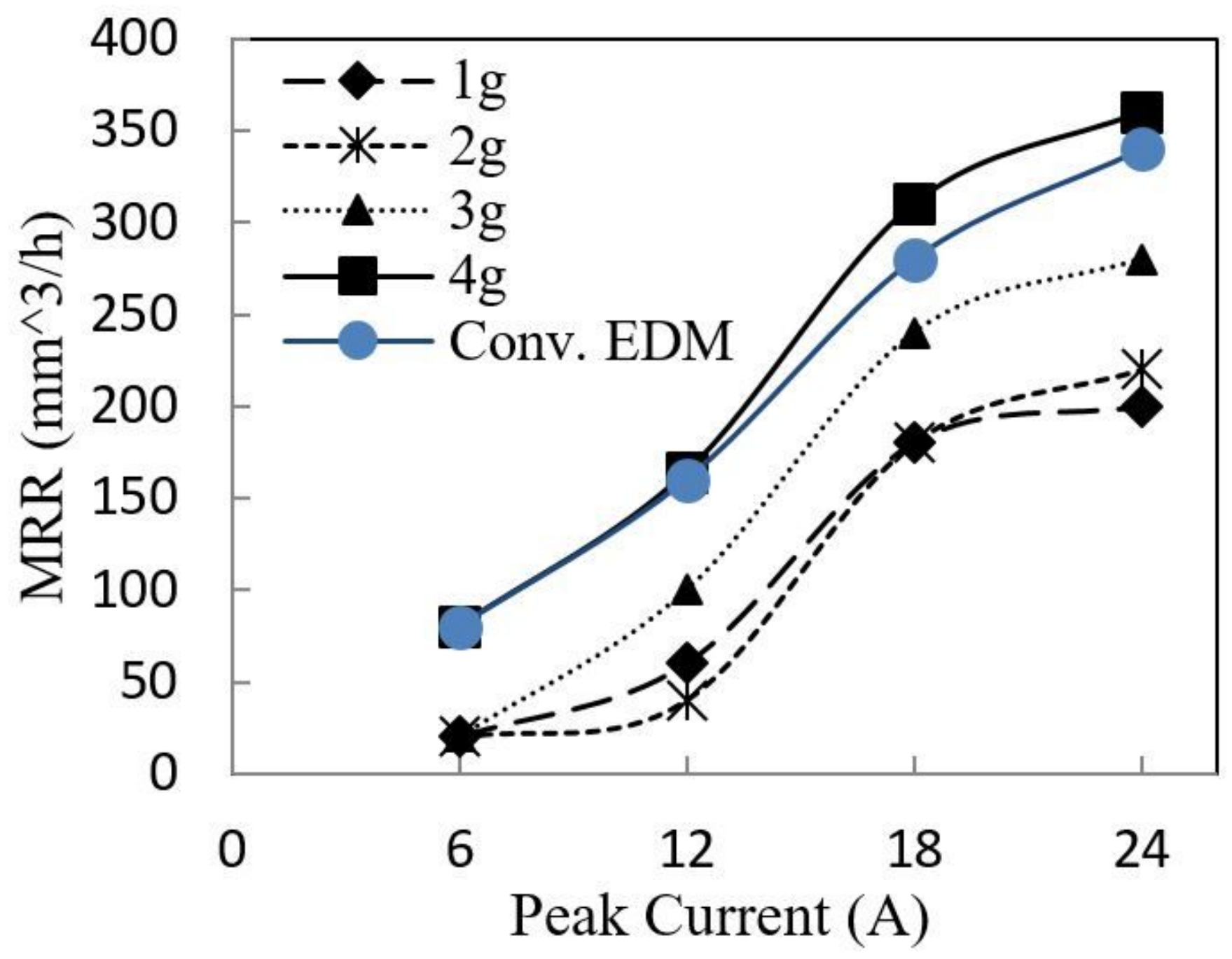

Figure 8

The variation of MRR for different peak currents and ZnO masses in NPMEDM of AISI 1045 


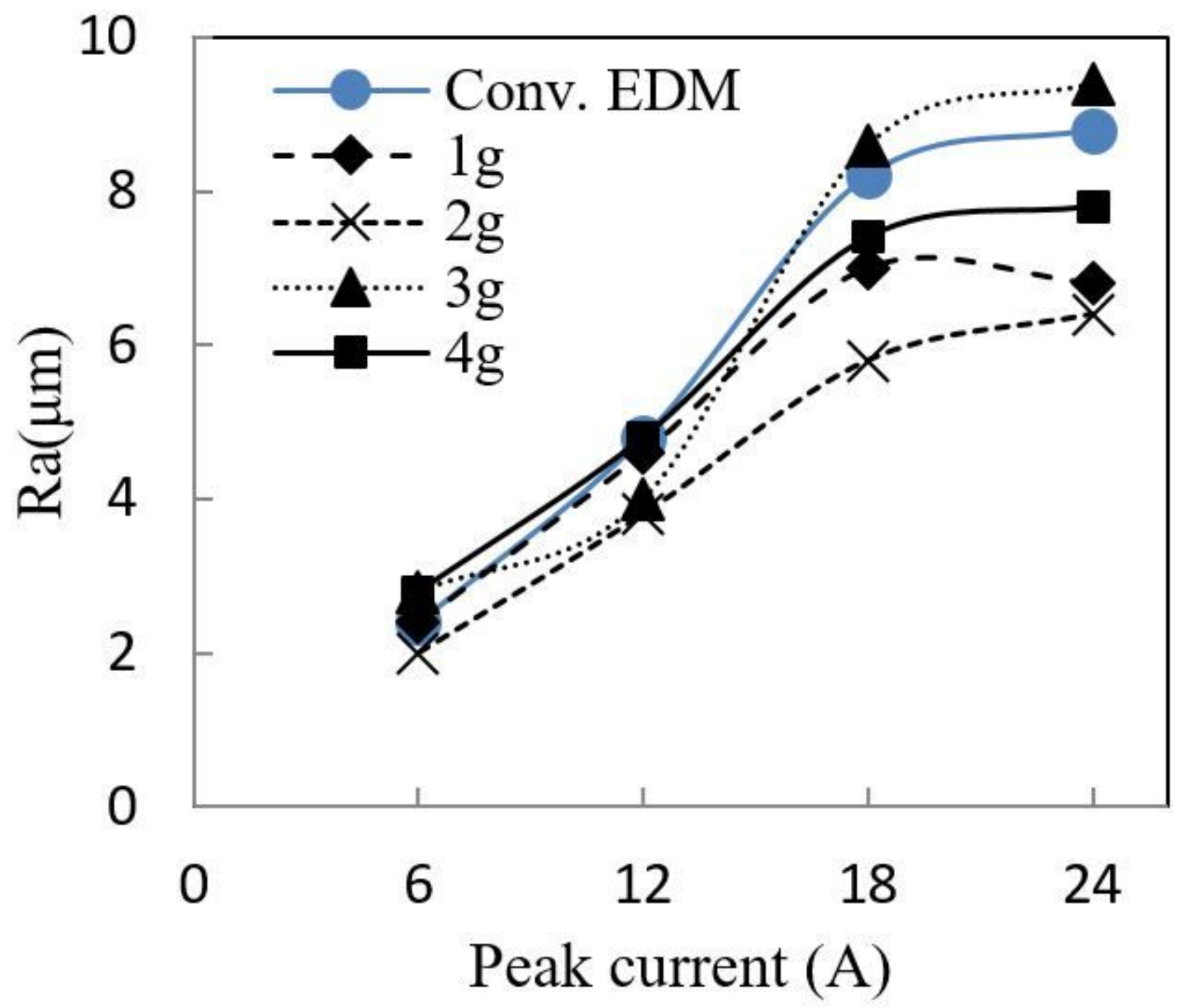

Figure 9

The variation of surface roughness for different peak currents and ZnO masses in NPMEDM of AISI 1045 


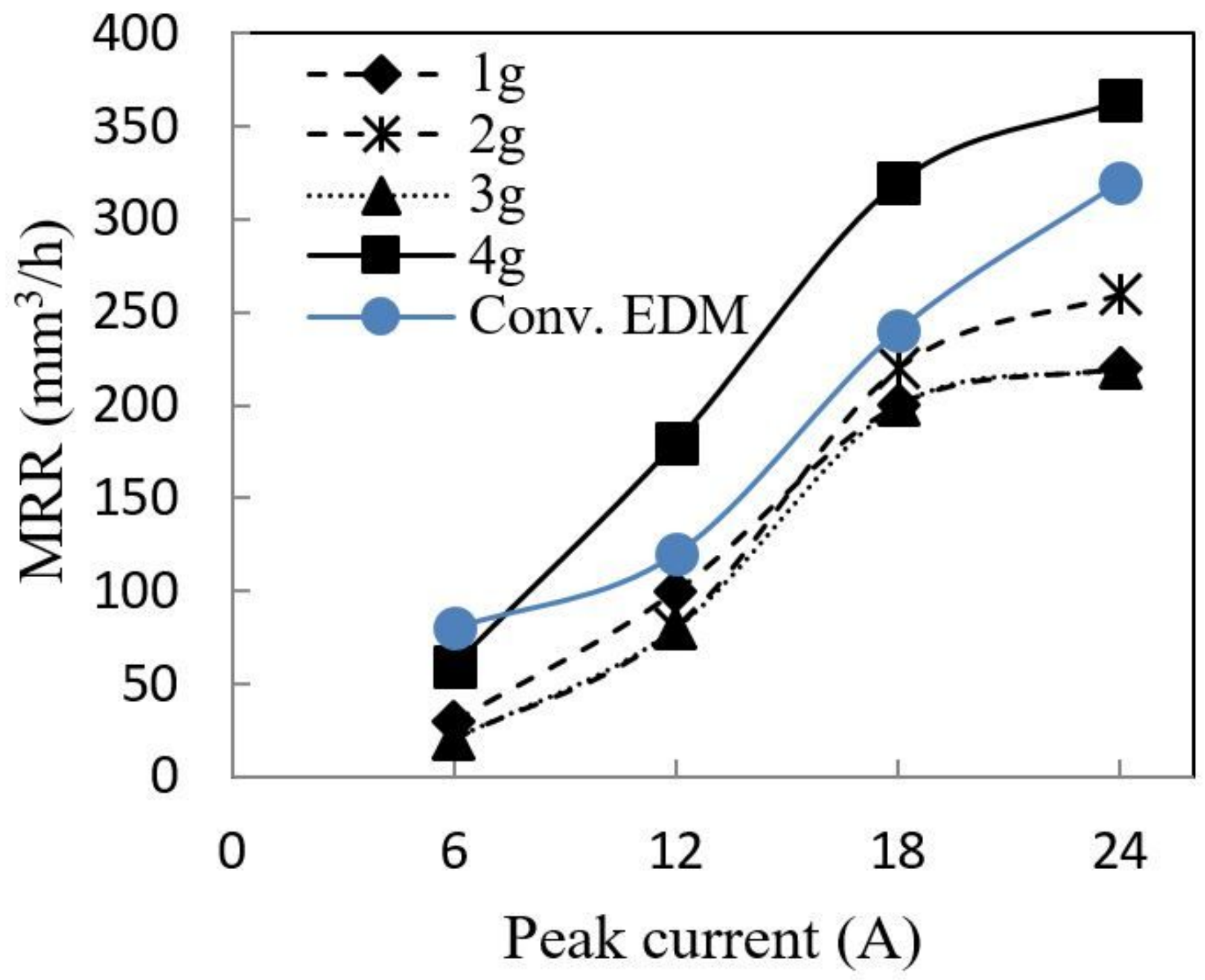

Figure 10

The variation of MRR for different peak currents and ZnO masses in NPMEDM of AISI 4140 


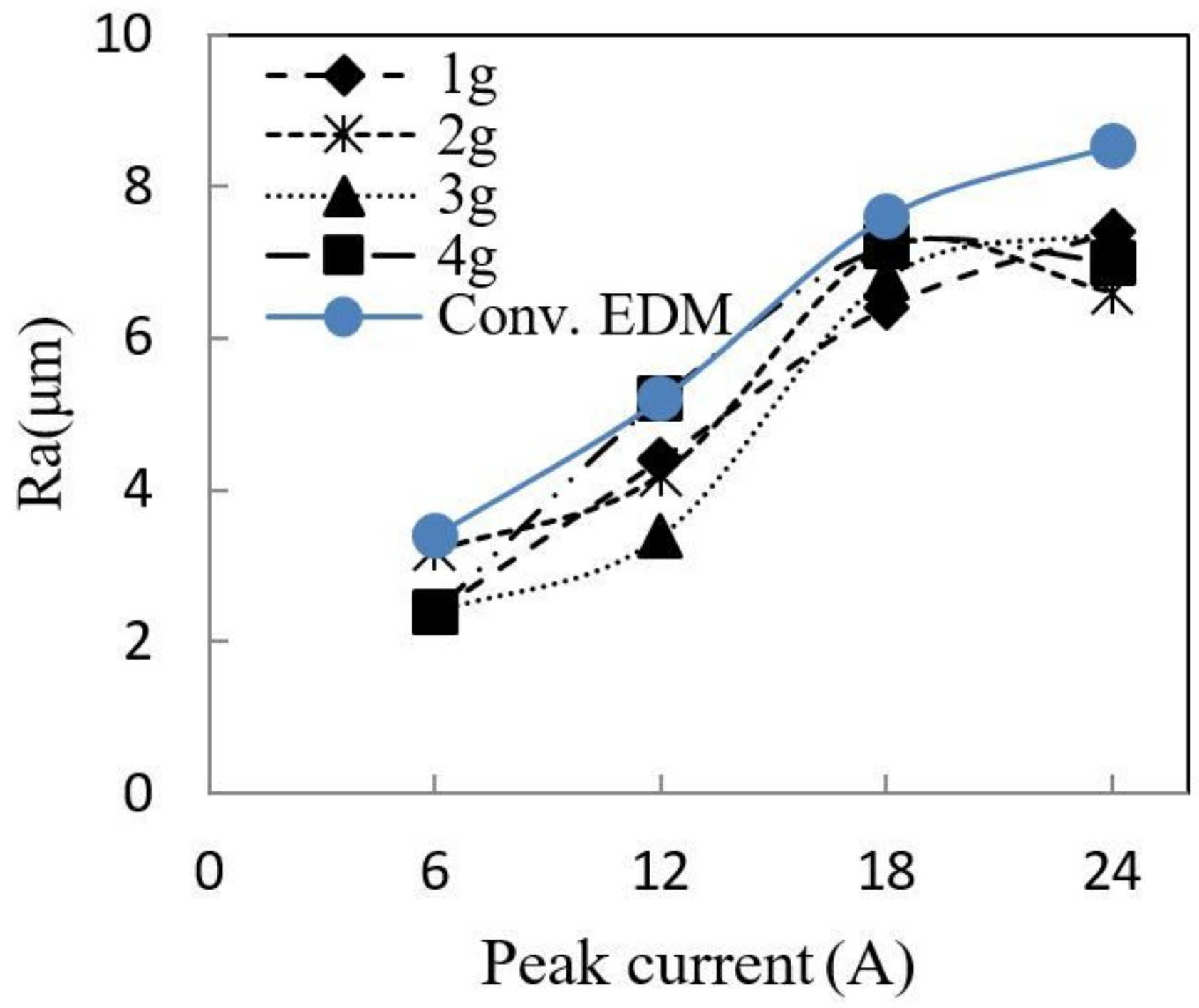

Figure 11

The variation of surface roughness for different peak currents and ZnO masses in NPMEDM of AISI 4140 


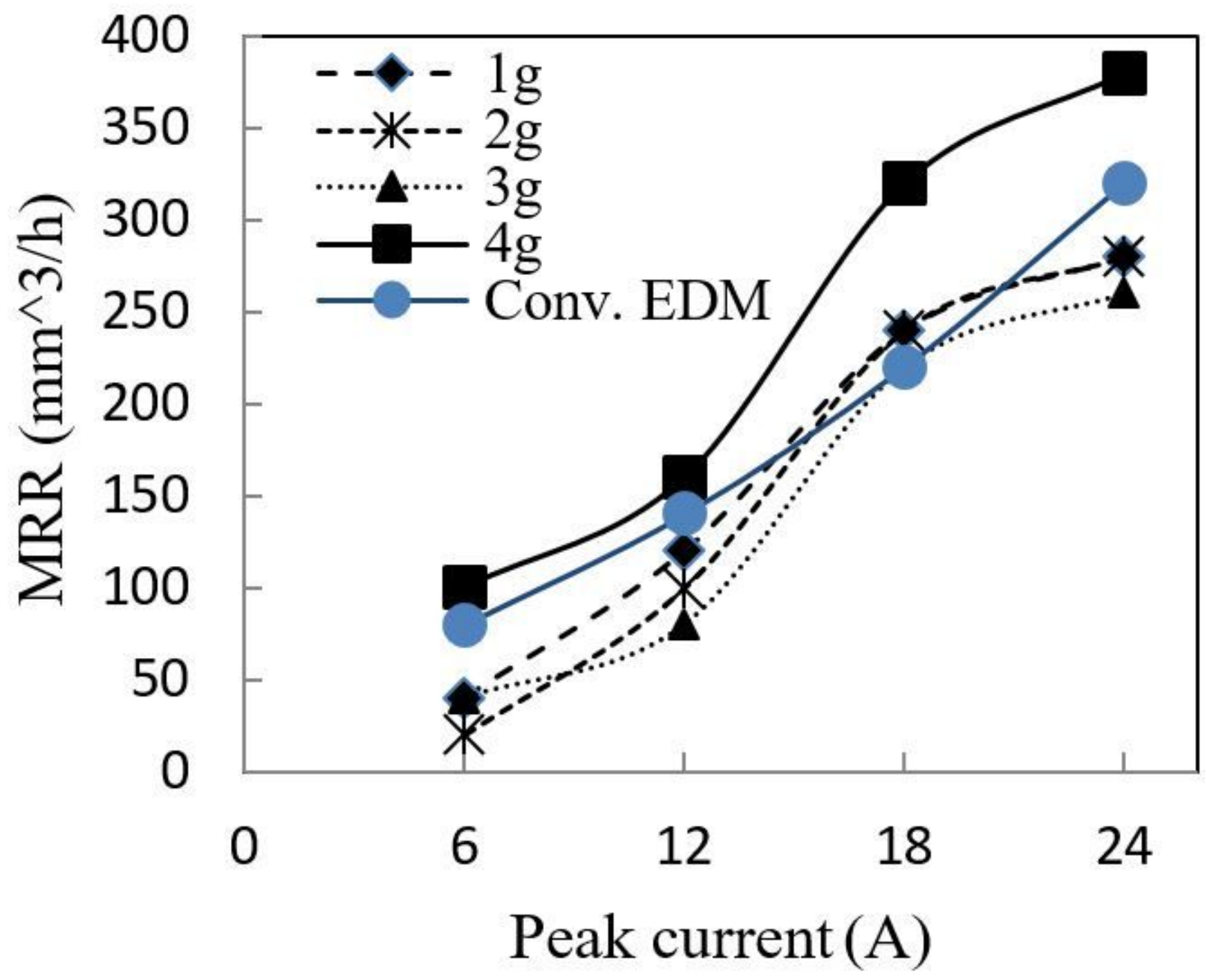

Figure 12

The variation of MRR for different peak currents and $\mathrm{ZnO}$ masses in NPMEDM of AISI D3 


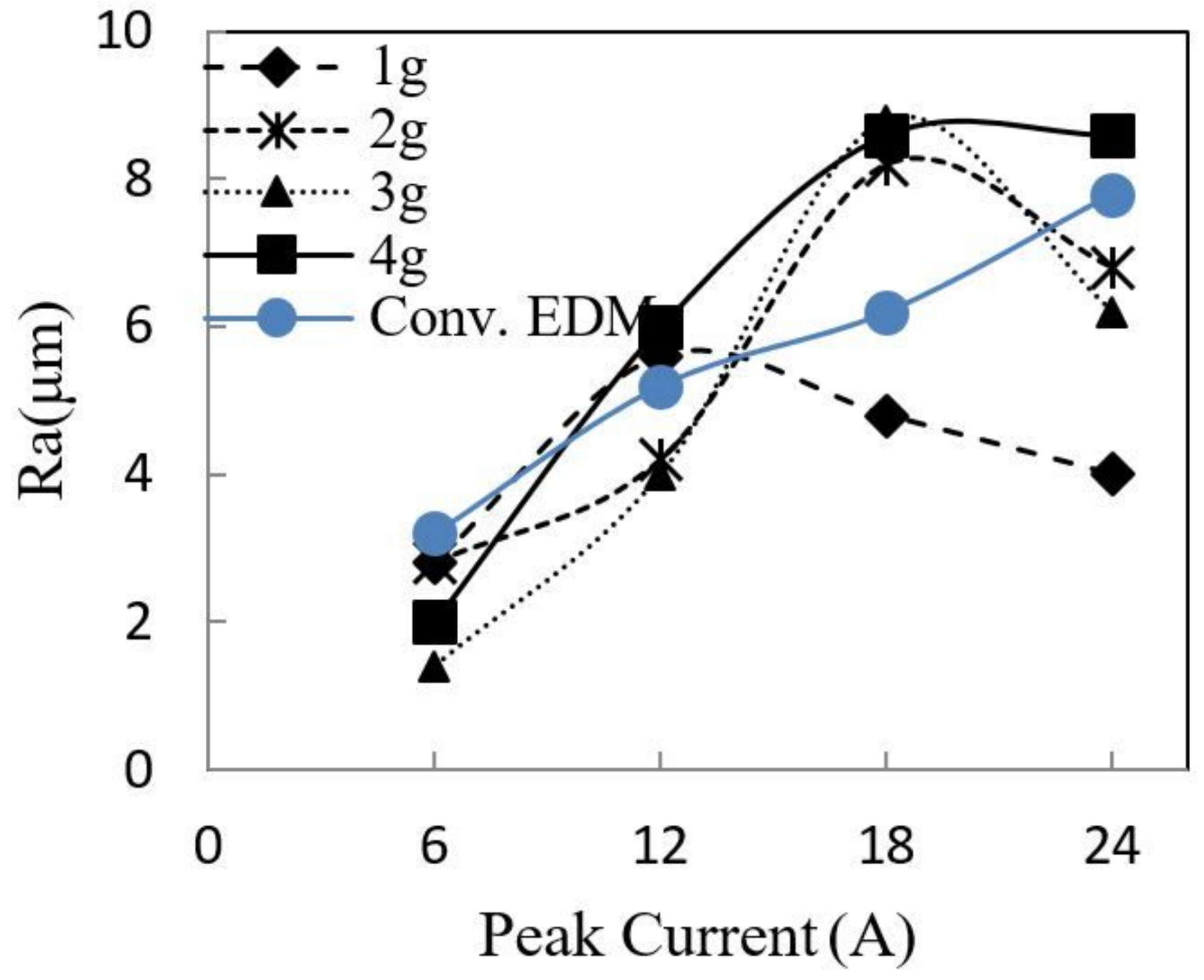

Figure 13

The variation of surface roughness for different peak currents and ZnO masses in NPMEDM of AISI D3 


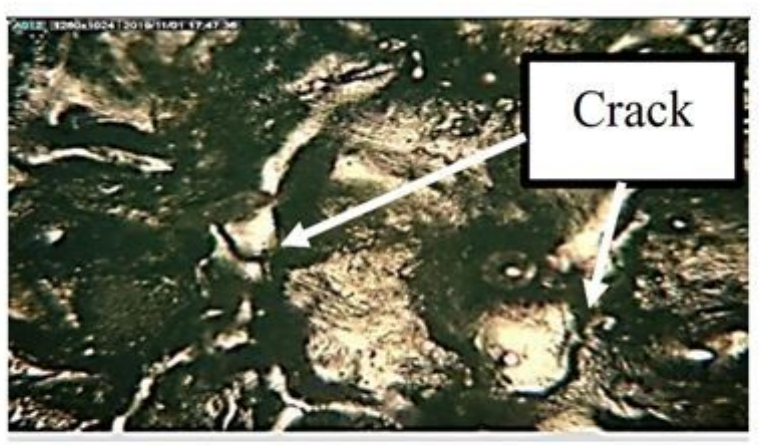

A) $\mathrm{ZnO}$ mass $=4 \mathrm{~g}$, peak current $=24 \mathrm{~A}$

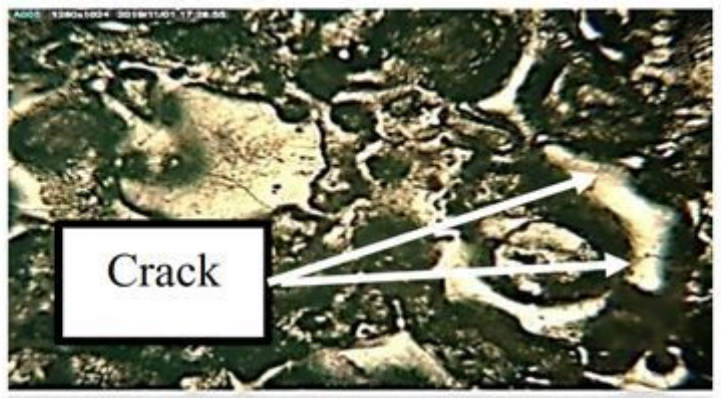

C) $\mathrm{ZnO}$ mass $=4 \mathrm{~g}$, peak current $=12 \mathrm{~A}$

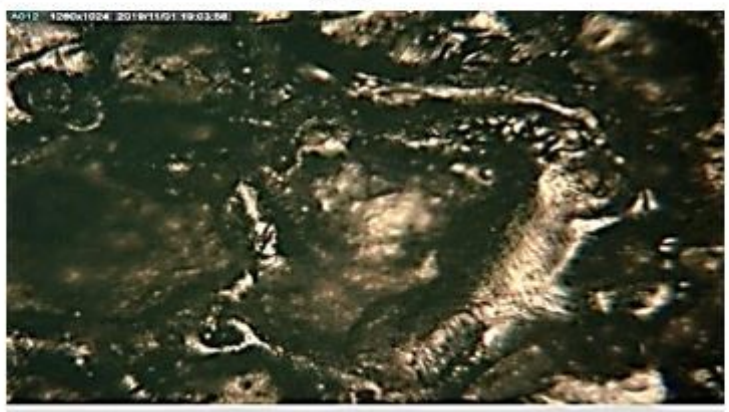

E) No $\mathrm{ZnO}$, peak current $=24 \mathrm{~A}$

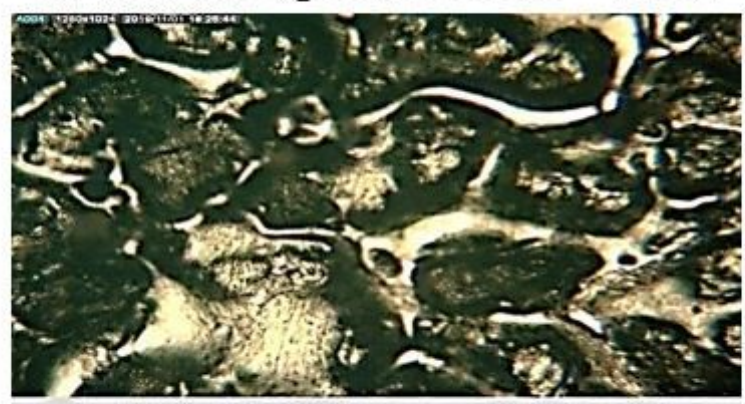

G) No $\mathrm{ZnO}$, peak current $=12 \mathrm{~A}$

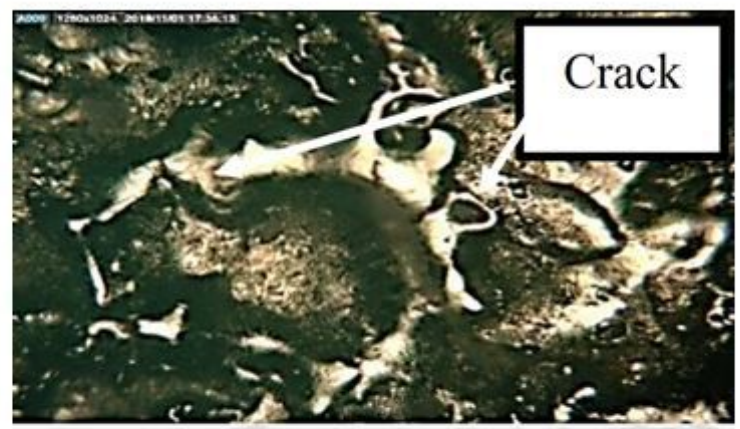

B) $\mathrm{ZnO}$ mass $=4 \mathrm{~g}$, peak current $=18 \mathrm{~A}$

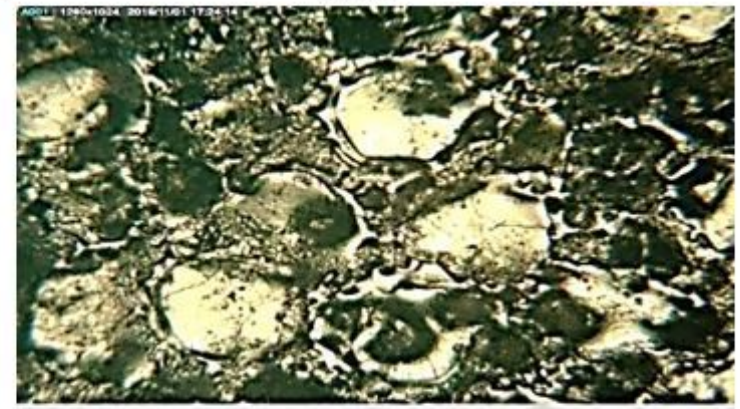

D) $\mathrm{ZnO}$ mass $=4 \mathrm{~g}$, peak current $=6 \mathrm{~A}$

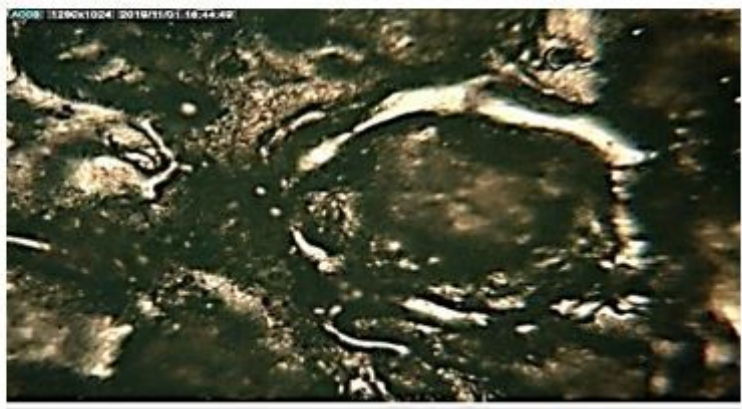

F) No $\mathrm{ZnO}$, peak current $=18 \mathrm{~A}$

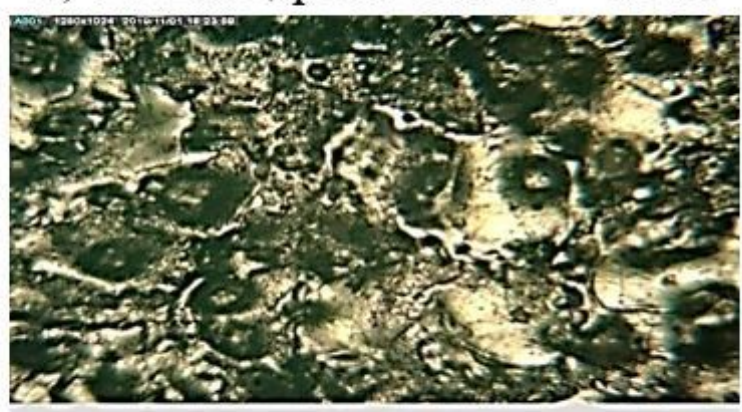

H) No $\mathrm{ZnO}$, peak current $=6 \mathrm{~A}$

Figure 14

The morphology of produced surface of AISI1045 using NPMEDM process 


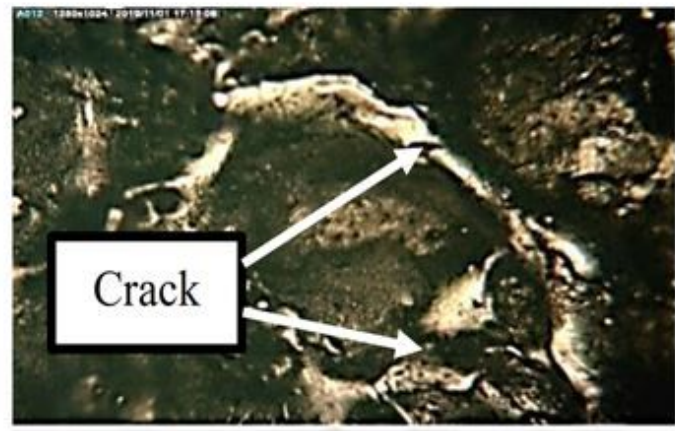

A) $\mathrm{ZnO}$ mass $=4 \mathrm{~g}$, peak current $=24 \mathrm{~A}$

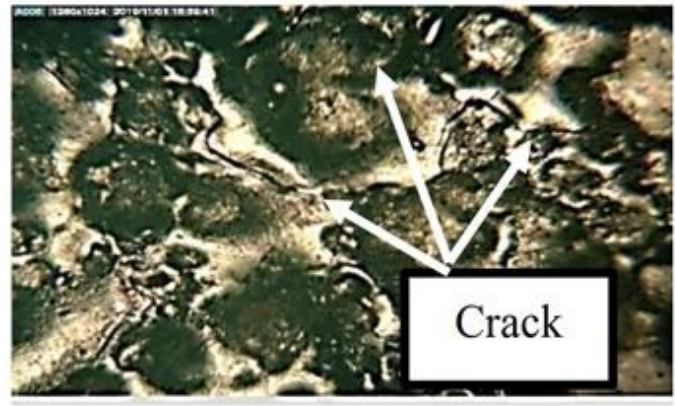

C) $\mathrm{ZnO}$ mass $=4 \mathrm{~g}$, peak current $=12 \mathrm{~A}$

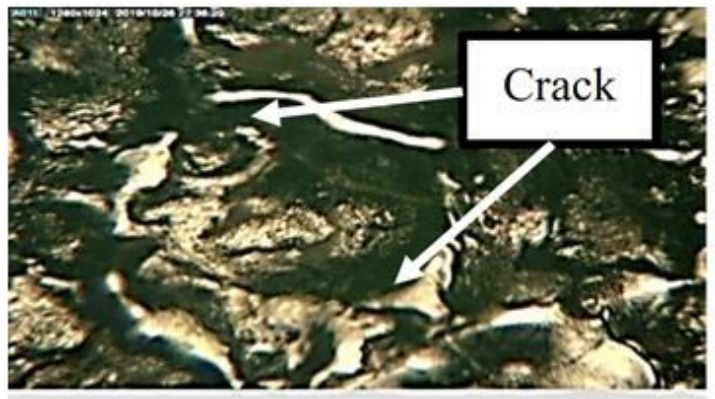

E) No $\mathrm{ZnO}$, peak current $=24 \mathrm{~A}$

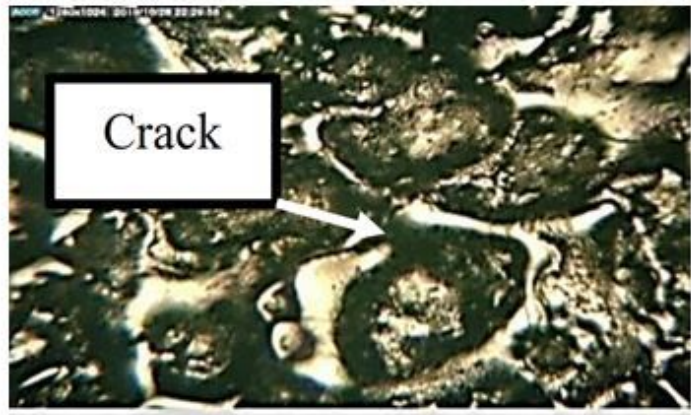

G) No $\mathrm{ZnO}$, peak current $=12 \mathrm{~A}$

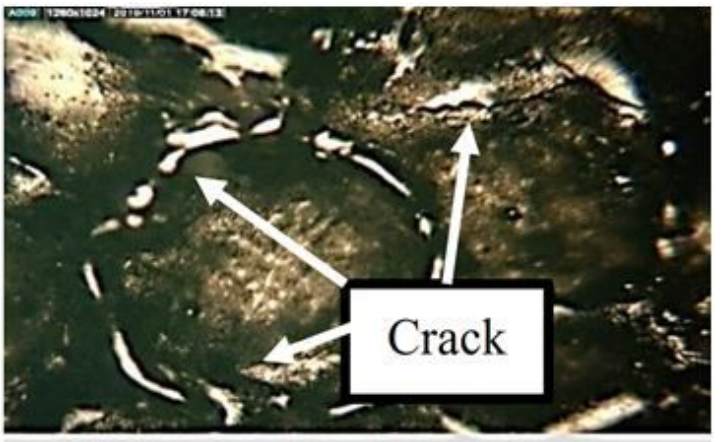

B) $\mathrm{ZnO}$ mass $=4 \mathrm{~g}$, peak current $=18 \mathrm{~A}$

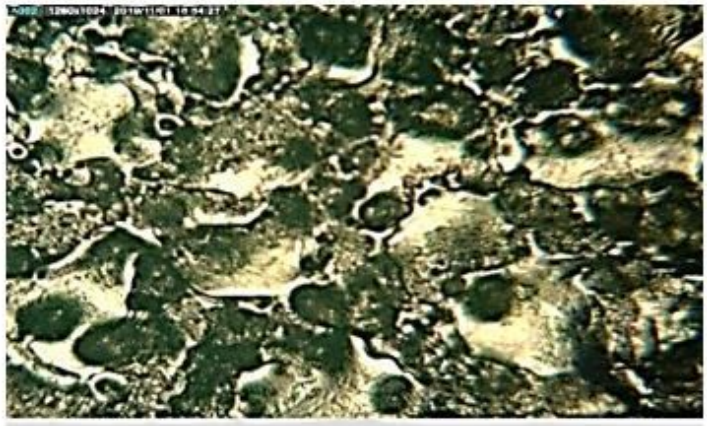

D) $\mathrm{ZnO}$ mass $=4 \mathrm{~g}$, peak current $=6 \mathrm{~A}$

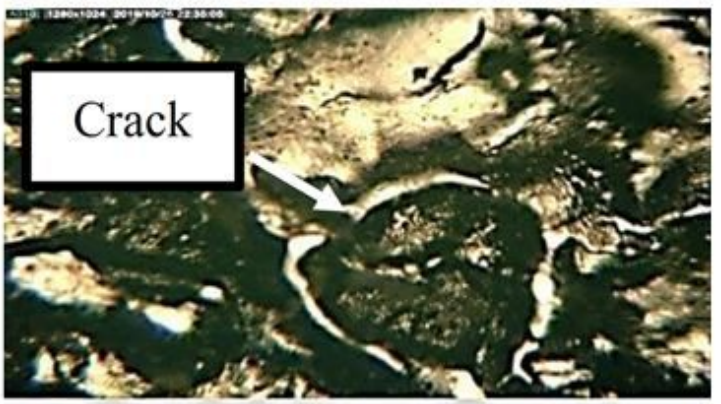

F) No $\mathrm{ZnO}$, peak current $=18 \mathrm{~A}$

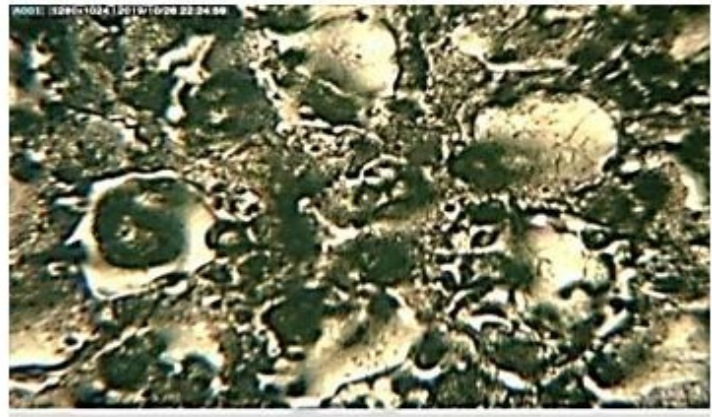

H) No $\mathrm{ZnO}$, peak current $=6 \mathrm{~A}$

Figure 15

The morphology of produced surface of AISI 4140 using NPMEDM process 


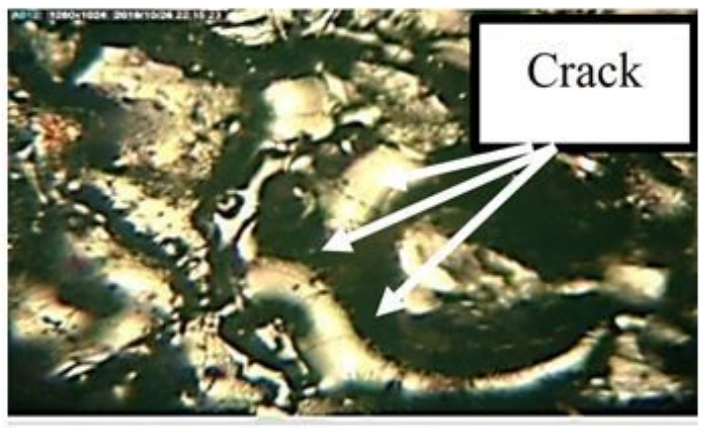

A) $\mathrm{ZnO}$ mass $=4 \mathrm{~g}$, peak current $=24 \mathrm{~A}$

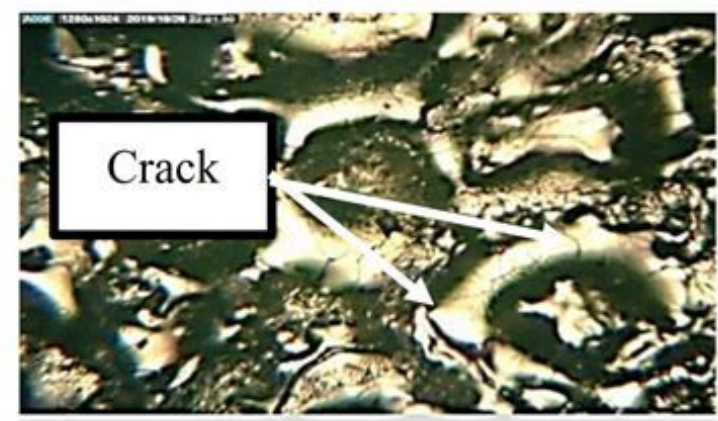

C) $\mathrm{ZnO}$ mass $=4 \mathrm{~g}$, peak current $=12 \mathrm{~A}$

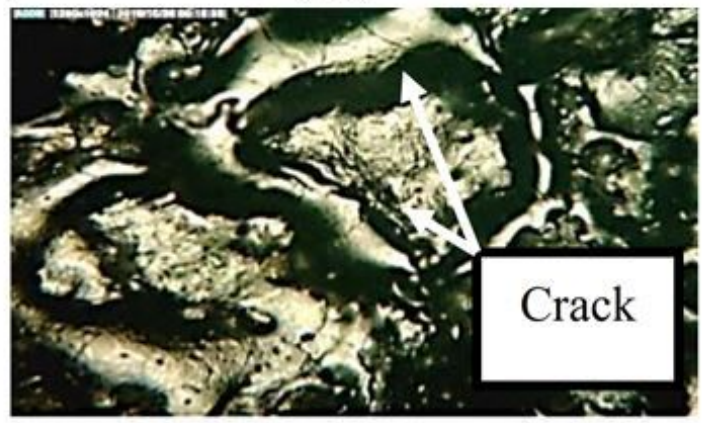

E) No $\mathrm{ZnO}$, peak current $=24 \mathrm{~A}$

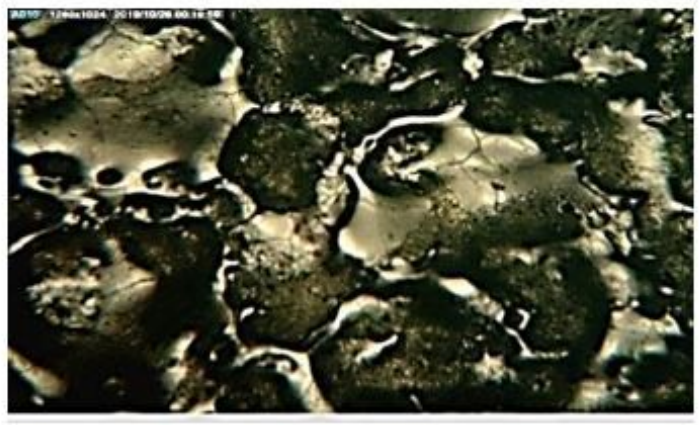

G) $\mathrm{No} \mathrm{ZnO}$, peak current $=12 \mathrm{~A}$

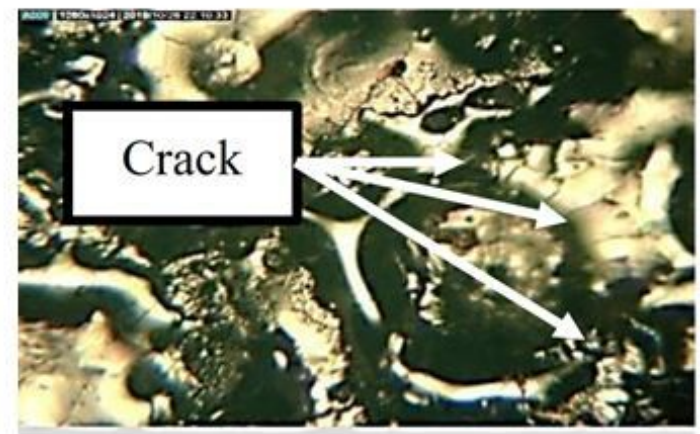

B) $\mathrm{ZnO}$ mass $=4 \mathrm{~g}$, peak current $=18 \mathrm{~A}$

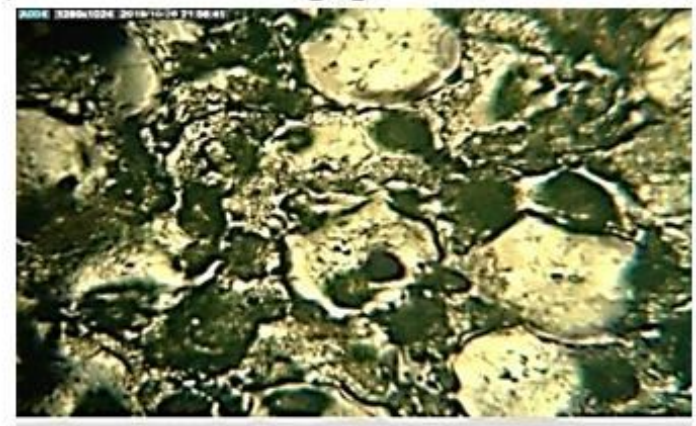

D) $\mathrm{ZnO}$ mass $=4 \mathrm{~g}$, peak current $=6 \mathrm{~A}$

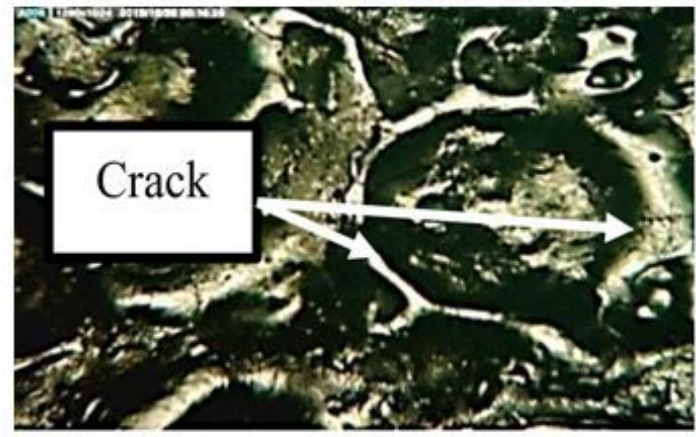

F) No $\mathrm{ZnO}$, peak current $=18 \mathrm{~A}$

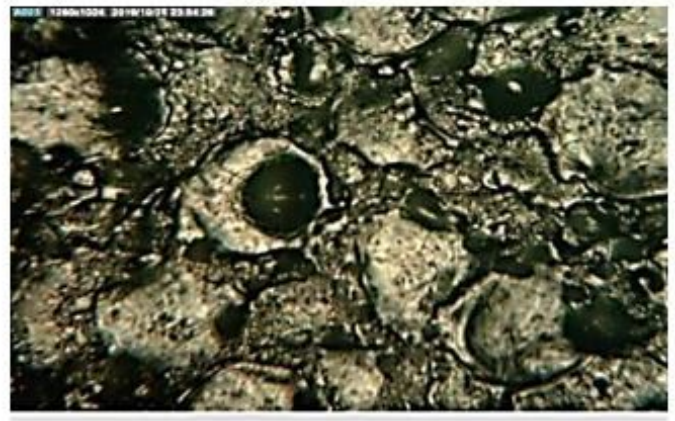

$\mathrm{H}) \mathrm{No} \mathrm{ZnO}$, peak current $=6 \mathrm{~A}$

Figure 16

The morphology of produced surface of AISI D3 using NPMEDM process 


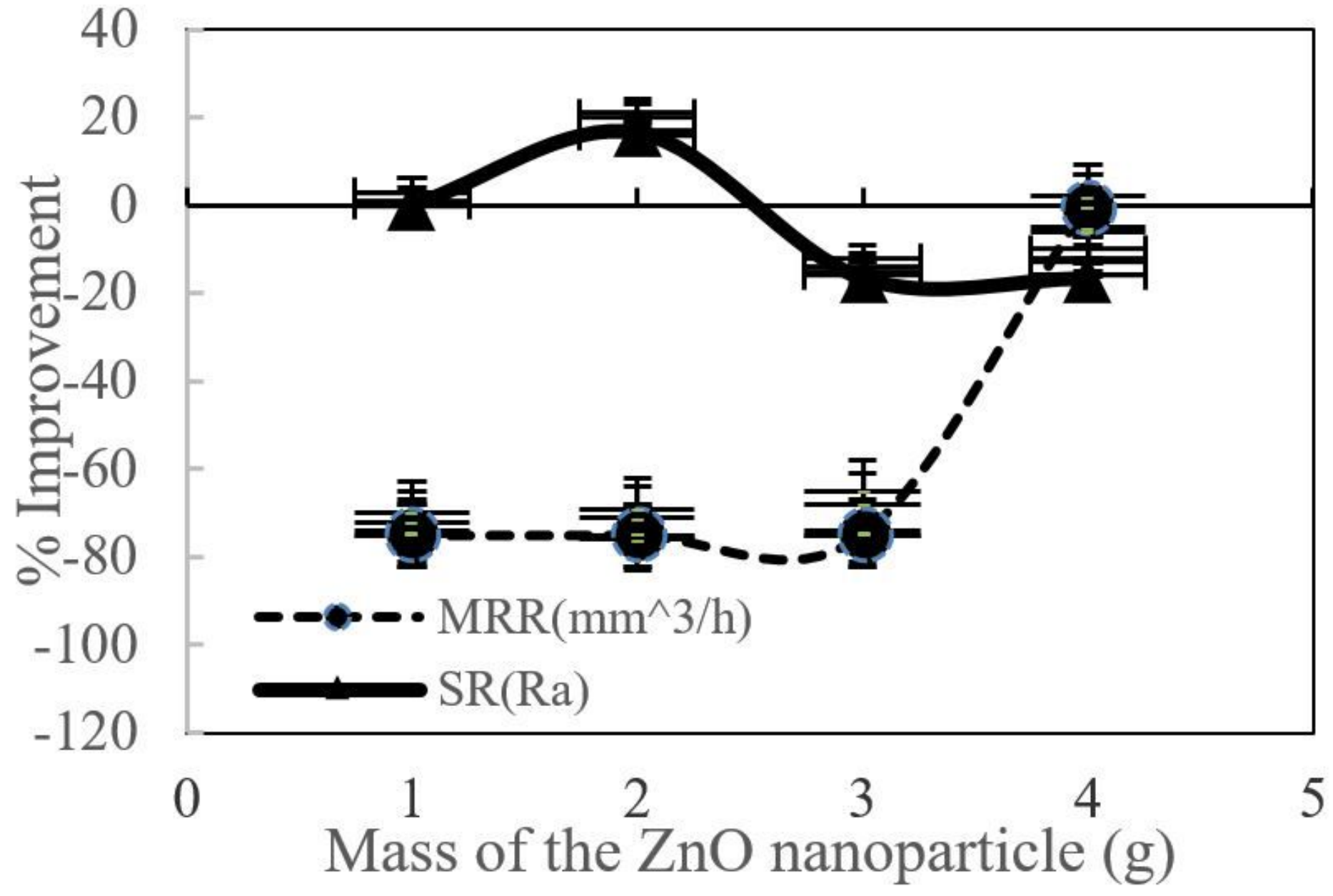

Figure 17

The improvement percentage of the MRR and surface roughness of AISI 1045 in NPMEDM using 6A current 


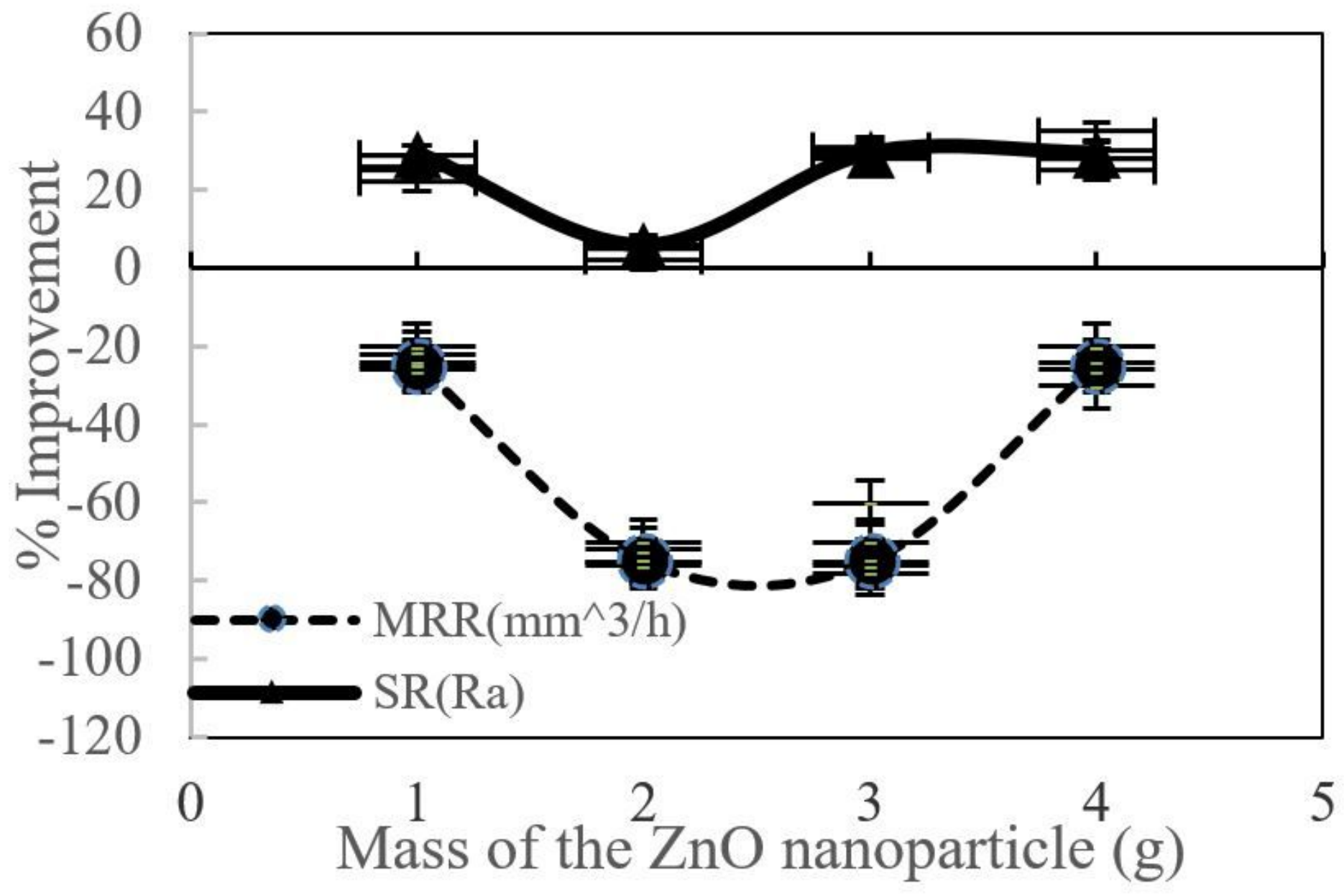

Figure 18

The improvement percentage of the MRR and surface roughness of AISI 4140 in NPMEDM using 6A current 


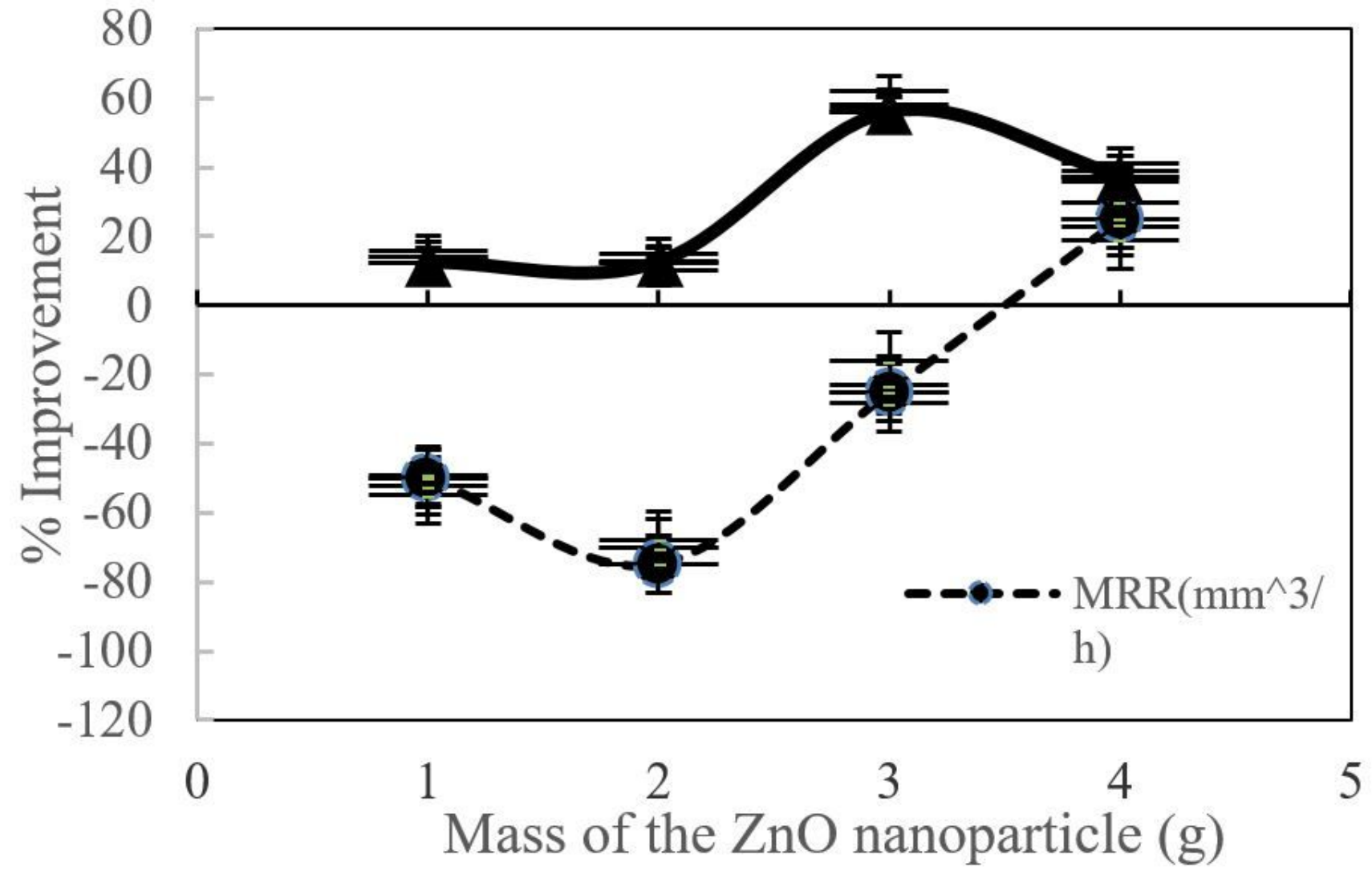

Figure 19

The improvement percentage of the MRR and surface roughness of AISID3 in NPMEDM using 6A current

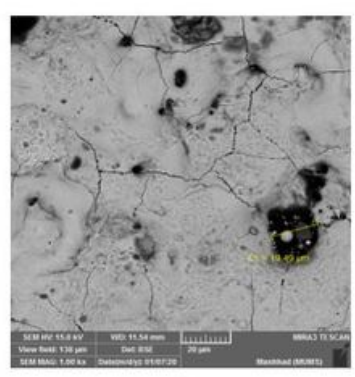

A) EDM

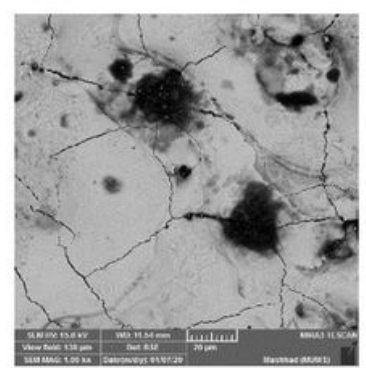

B) $1 \mathrm{~g} \mathrm{ZnO}$

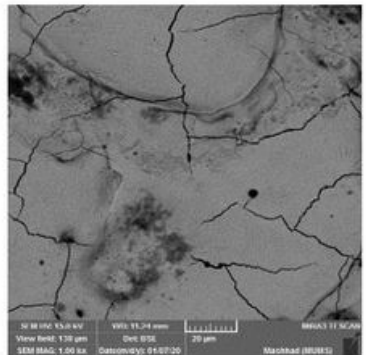

C) $2 \mathrm{~g} \mathrm{ZnO}$

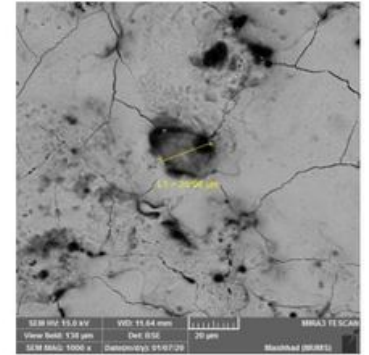

D) $3 \mathrm{~g} \mathrm{ZnO}$

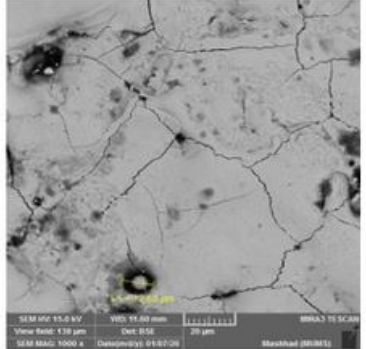

E) $4 \mathrm{~g} \mathrm{ZnO}$

Figure 20

The SEM images of AISI 1045 machined surface using peak current 6A and different mass of ZnO 


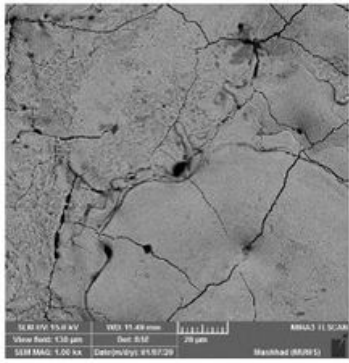

A)EDM

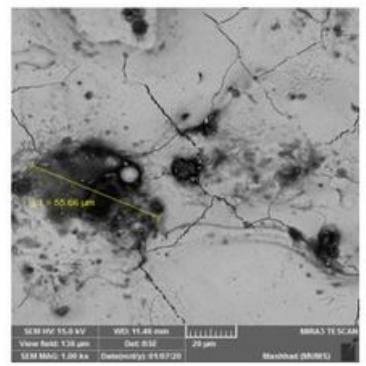

B) $1 \mathrm{~g} \mathrm{ZnO}$

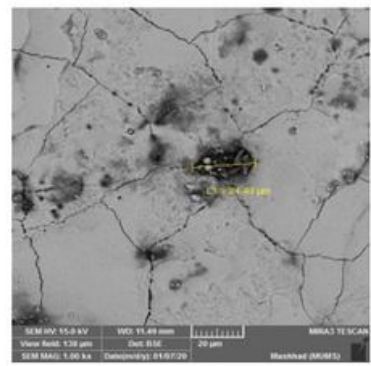

C) $2 \mathrm{~g} \mathrm{ZnO}$

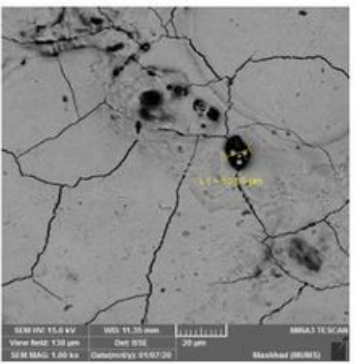

D) $3 \mathrm{~g} \mathrm{ZnO}$

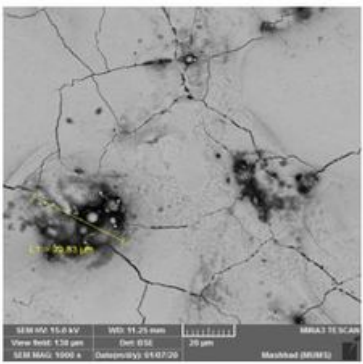

E) $4 \mathrm{~g} \mathrm{ZnO}$

Figure 21

The SEM images of AISI 4140 machined surface using peak current $6 \mathrm{~A}$ and different mass of ZnO

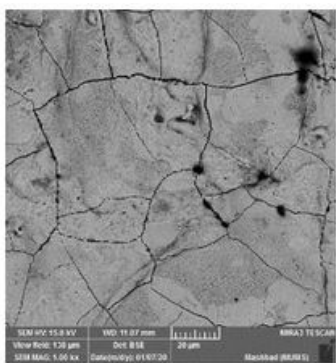

A)EDM

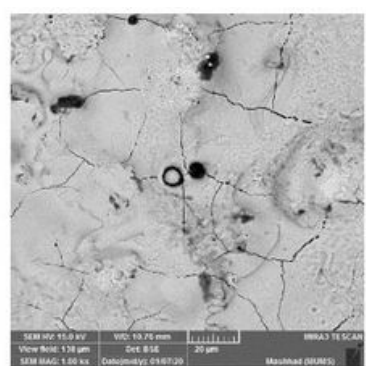

B) $1 \mathrm{~g} \mathrm{ZnO}$

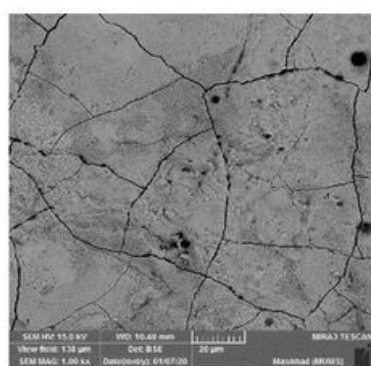

C) $2 \mathrm{~g} \mathrm{ZnO}$

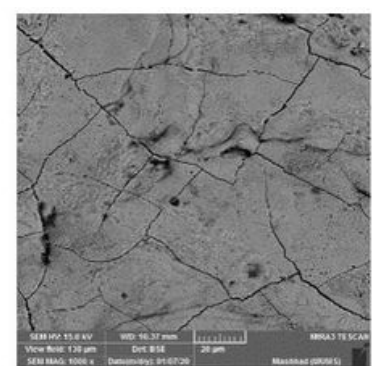

D) $3 \mathrm{~g} \mathrm{ZnO}$

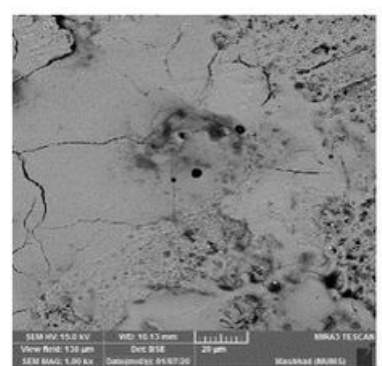

E) $4 \mathrm{~g} \mathrm{ZnO}$

\section{Figure 22}

The SEM images of AISI D3 machined surface using peak current $6 \mathrm{~A}$ and different mass of ZnO

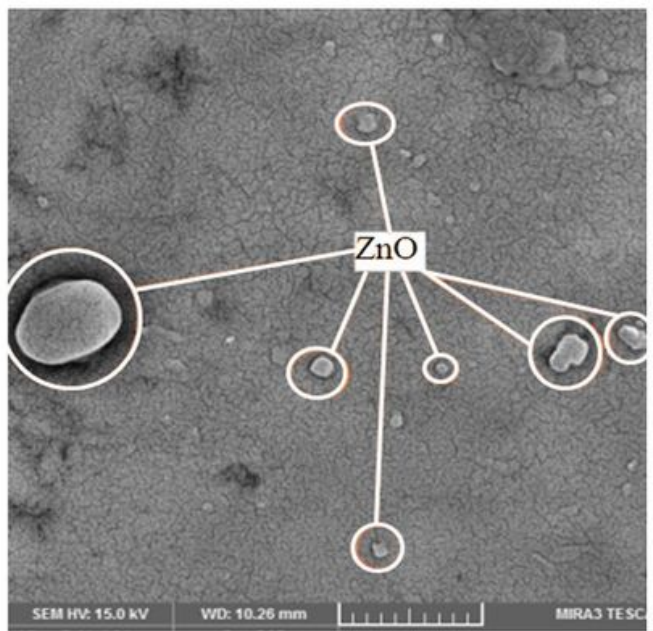

A)

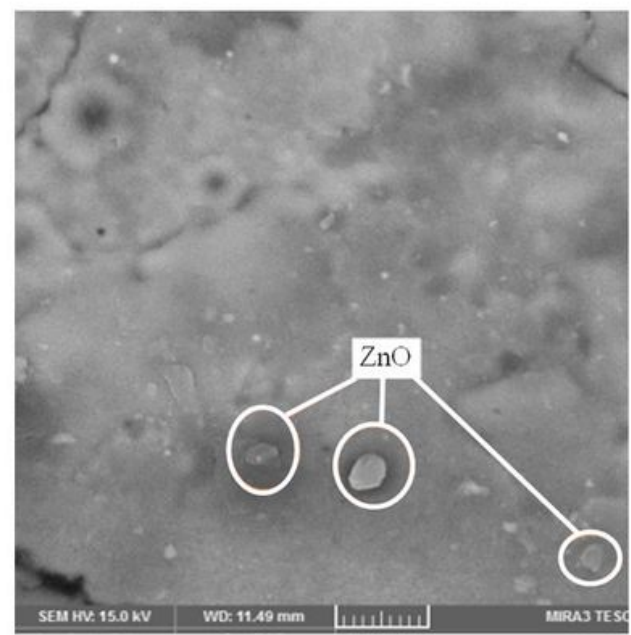

B)

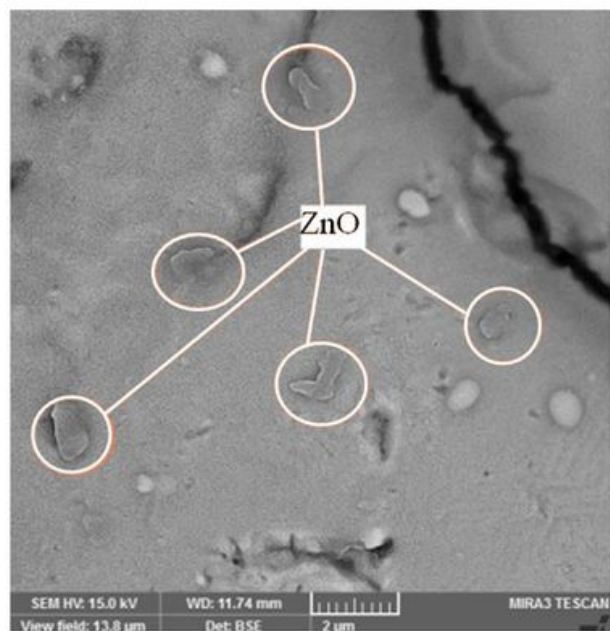

C)

\section{Figure 23}

the deposit of the ZnO nanoparticles on surface of A) AISI D3 B) AISI 4140 and C) AISI 1045 


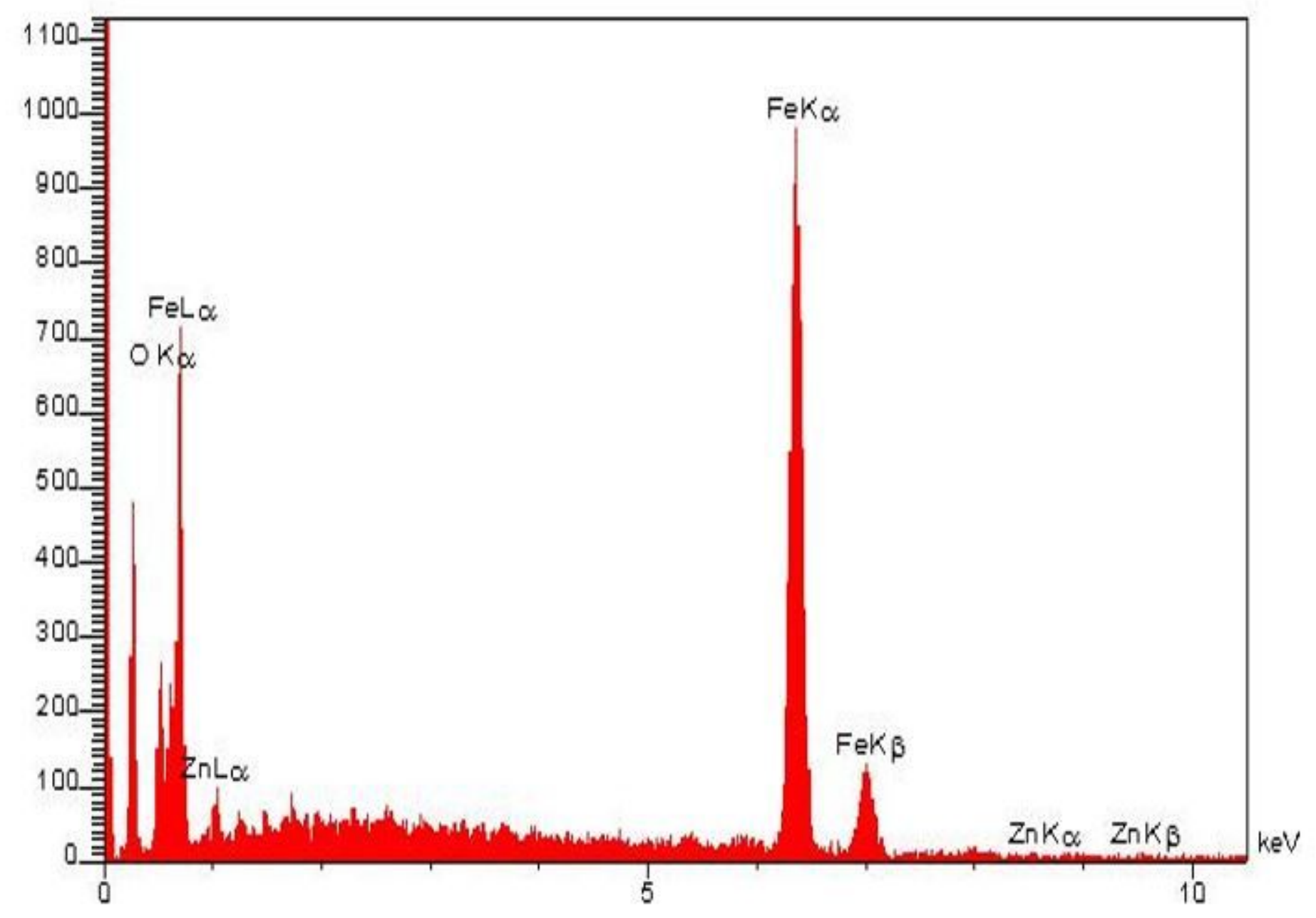

Figure 24

The distribution of material on the AISI D3 in figure 26-A 


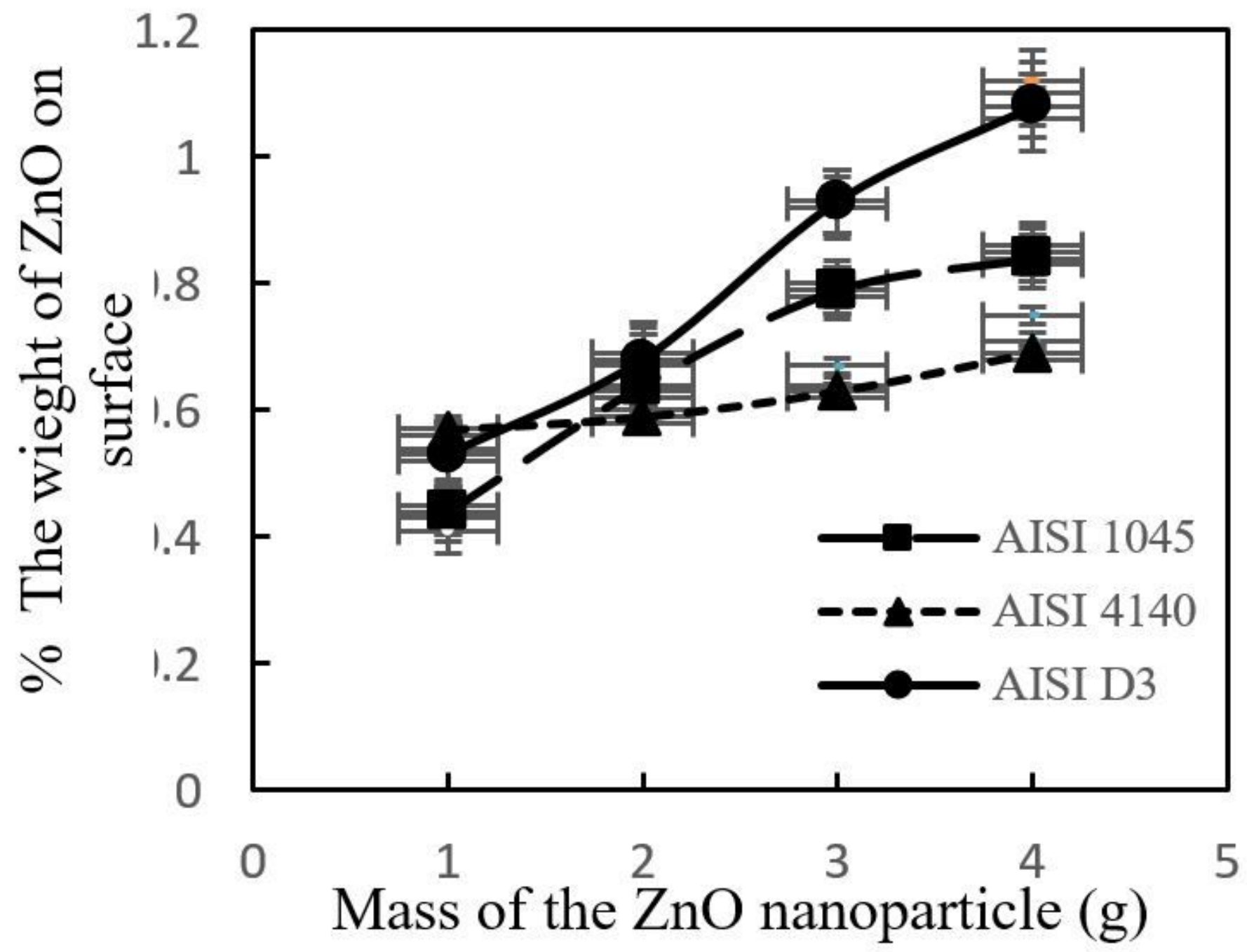

Figure 25

The variation of deposit of $\mathrm{ZnO}$ in different steels 